\title{
24 Anemonefishes
}

\author{
Marleen Klann, Manon Mercader, Pauline Salis, Mathieu Reynaud, \\ Natacha Roux, Vincent Laudet and Laurence Besseau
}

\section{CONTENTS}

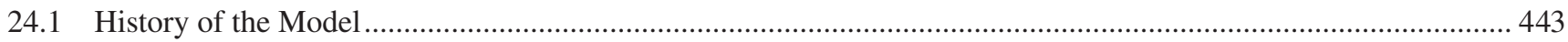

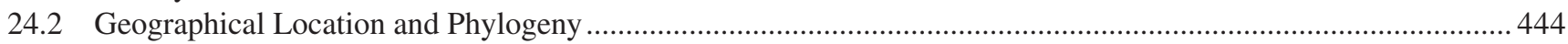

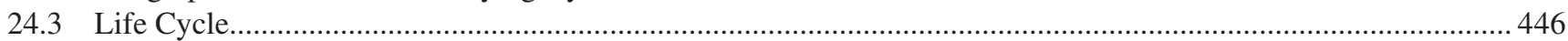

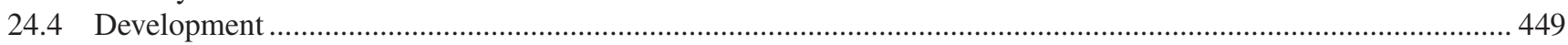

24.4.1 Embryonic Stage 1: Early Cleavages (Figure 24.4a) ........................................................................... 449

24.4.2 Embryonic Stage 2: Late Cleavages (Figure 24.4b) ……..................................................................... 449

24.4.3 Embryonic Stage 3: Gastrulation (Figure 24.4c) ............................................................................... 450

24.4.4 Embryonic Stage 4: Cephalization and Somite Development (Figure 24.4d) .......................................451

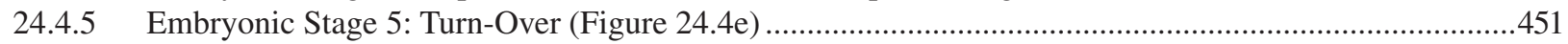

24.4.6 Embryonic Stage 6: Blood Formation (Figure 24.4f) .........................................................................451

24.4.7 Embryonic Stage 7: Remaining Organ and Fin Development (Figure 24.4g)......................................451

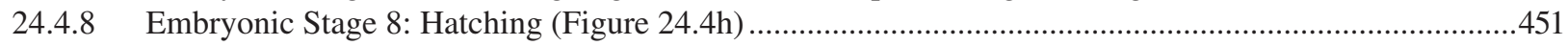

24.4.9 Larval Stage 1: Preflexion of the Notochord (Figure 24.4i) .................................................................451

24.4.10 Larval Stage 2: Flexion of the Notochord (Figure 24.4k).................................................................451

24.4.11 Larval Stage 3: Postflexion of the Notochord (Figure 24.41) ................................................................451

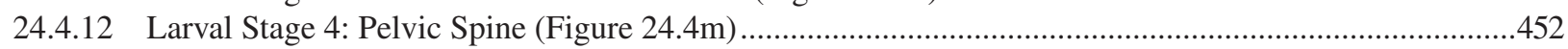

24.4.13 Larval Stage 5: Appearance of White Bands (Figure 24.4n) ...............................................................452

24.4.14 Larval Stage 6: Maturation of Adult Color Pattern (Figure 24.4o) .........................................................452

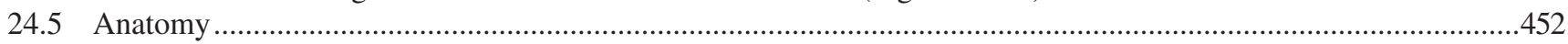

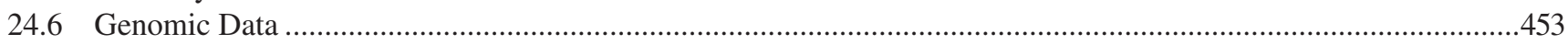

24.7 Functional Approaches: Tools for Molecular and Cellular Analysis .................................................................... 454

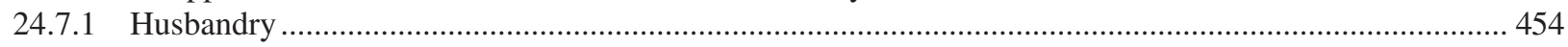

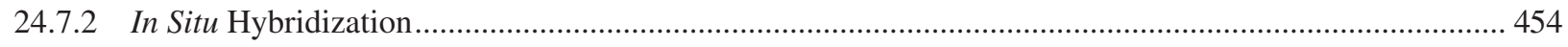

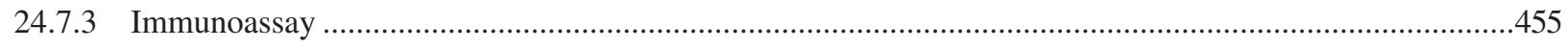

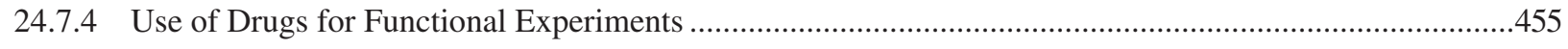

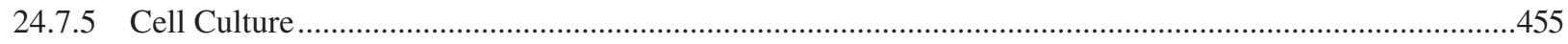

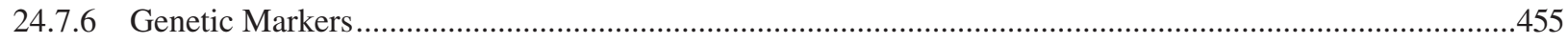

24.8 Challenging Questions, Both in Academic and Applied Research ........................................................................455

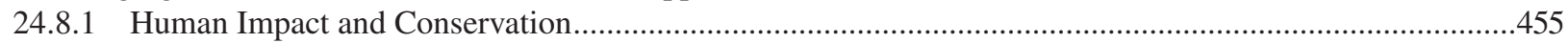

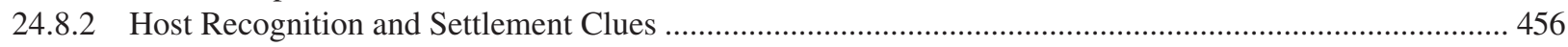

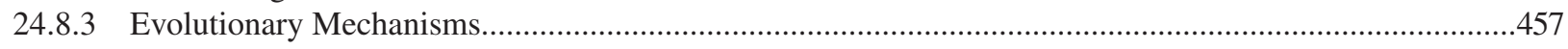

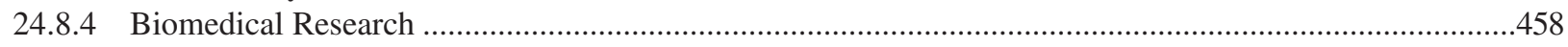

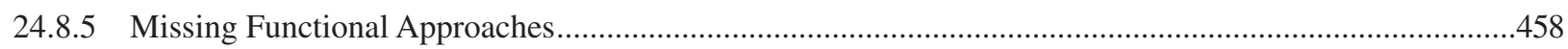

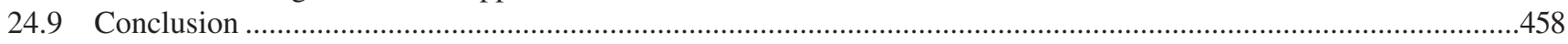

Note

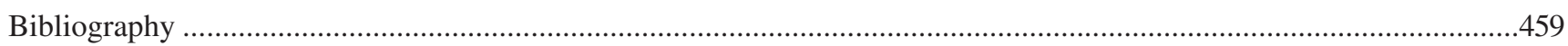

\subsection{HISTORY OF THE MODEL}

I noticed a very pretty little fish which hovered in the water close by, and nearly over the anemone. This fish was six inches long, the head bright orange, and the body vertically banded with broad rings of opaque white and orange alternately, three bands of each. As the fish remained stationary, and did not appear to be alarmed at my movements, I made several attempts to catch it; but it always eluded my efforts, not darting away, however, as might be expected, but always returning presently to the same spot. ... I visited from time to time the place where the anemone was fixed, and each time, in spite of all my disturbance of it, I found the little fish there also. This singular persistence of the fish to the same spot, and to the close vicinity of 


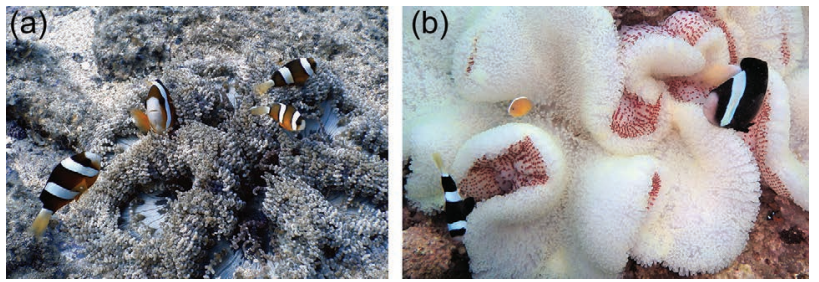

FIGURE 24.1 Colony of $A$. clarkii (a) and cohabitation of $A$. clarkii and A. sandaracinos (b) in Okinawa, Japan. ([a] Photo courtesy of Manon Mercader; [b] photo courtesy of Kina Hayashi.)

the great anemone, aroused in me strong suspicions of the existence of some connection between them.

\section{(Collingwood 1868)}

This is the first written description of an anemonefish ${ }^{*}$ (Figure 24.1) and its peculiar lifestyle, observed by English naturalist Cuthbert Collingwood in 1866 at Fiery Cross Reef off the coast of Borneo. The remarkable symbiosis between anemonefishes and giant sea anemones has since then received a lot of attention, becoming one of the main examples of mutualistic interactions (Apprill 2020). It is actually the keen interest for this interaction that first drove scientists to study these fish (Mariscal 1970; Lubbock and Smith 1980; Fautin 1991), but, as scuba diving became popular, rending shallow environments easily accessible, multiple aspects of their biology and ecology soon started to be investigated (Mariscal 1970; Allen 1974; Moyer 1980; Ochi 1985; Murata et al. 1986). Indeed, anemonefishes are unthought-of models for marine ecologists as, unlike many marine fishes, they can be easily located at a given site as well as followed through time. Besides, they are also relatively easy to capture and, being one of the most iconic tropical reef fish species, they quickly became a must-have for aquarium hobbyists. They were one of the first captive-bred marine fish back in the 1970s, and now, many species as well as a variety of fancy mutants can easily be found in pet shops. This combination of efficient rearing and convenient sampling possibilities makes anemonefishes excellent model organisms not only for marine ecologists but also for a multitude of biological fields (reviewed in Roux et al. 2020). Until now, studies on behavior (Buston 2003a; Rueger et al. 2018), physiology (Park et al. 2011; Miura et al. 2013), development (Salis et al. 2018b; Roux et al. 2019b), evolution (Litsios et al. 2012a; Rolland et al. 2018) and population dynamics (Nanninga et al. 2015; Salles et al. 2015), just to mention a few, have been conducted using anemonefishes.

\subsection{GEOGRAPHICAL LOCATION AND PHYLOGENY}

Anemonefishes form a clade of at least 30 species in genera Premnas and Amphiprion, including two species that are natural hybrids (A. leukokranos [A. sandaracinos $\mathrm{X} A$.

\footnotetext{
The term anemonefi shes, rather than clownfi shes, is used in this chapter to refer to Amphiprion and Premnas even though other fi shes (pomacentrid and also non-pomacentrid; Randall \& Fautin 2002) can eventually live in sea anemones. This choice was made to avoid confusion due to the variety of common names employed for the different species of this clade.
}

chrysopterus] and A. thiellei [A. sandaracinos X A. ocellaris]) within the Pomacentridae family (Frédérich and Parmentier 2016). All are living as symbionts with ten sea anemone species that belong to three distantly related families (Thalassianthidae, Actinidae, Stichodactilidae) (Allen 1974; Fautin and Allen 1997; Ollerton et al. 2007; Allen et al. 2008 , 2010). This mutualistic relationship is the driving force of their diversification through adaptive radiation (Litsios et al. 2012b). However, diversification of giant sea anemones occurred before the establishment of this symbiotic relationship. Since their taxonomy is still unclear, the specificity between anemonefishes and their hosts will likely be revisited (Titus et al. 2019; Nguyen et al. 2020).

Historically, anemonefishes were categorized into six morphology-based groups; genus Premnas formed a group on its own, and Amphiprion was divided into four subgenera: Actinicola, Paramphiprion, Phalerebus and Amphiprion (the last one sub-divided into two species complex: ephippiumcomplex and clarkii-complex) (Allen 1974; Allen et al. 2008, 2010). It was also believed that the ancestral anemonefish was able to live in association with multiple sea anemone species (i.e. generalist) that later radiated into various more specialized species (Elliott et al. 1999). This process is commonly used to explain the evolution of symbiotic organisms (Futuyma and Moreno 1988). A. clarkii was then believed to be at the base of the anemonefish phylogenetic tree, as it is the most widespread and generalist species of the tribe. It is also less dependent on its host sea anemone due to its good swimming performance and its morphology, which resembles that of other free-living pomacentrids. However, the latest molecular phylogenetic studies do not support those hypotheses based on morphological traits. They support the monophyletic origin of anemonefish species, but the topologies found are inconsistent with the grouping into the six complexes mentioned previously. They also place A. percula and A. ocellaris, both specialists and poor swimmers, at the basal node of the tree (Santini and Polacco 2006; Litsios et al. 2012a, 2014b) (Figure 24.2a).

All 30 species of anemonefish inhabit coral reef environments in the warm, tropical waters of the Indo-Pacific Ocean, from Australia to the Ryukyu archipelago and from Thailand to the Marshall Islands (Figure 24.2 B) (Allen 1974; Fautin and Allen 1992, 1997; Allen et al. 2008, 2010). Distribution varies greatly from one species to another, with some being widespread (e.g. A. clarkii, P. biaculeatus) (Figure 24.2c), while others have a restricted regional distribution (e.g. A. bicinctus, A. percula) (Figure 24.2d) or are even confined to a few islands (e.g. A. chagosensis, A. fuscocaudatus) (Figure 24.2e). The highest diversity is found in the Coral Triangle (Fautin 1988; Elliott \& Mariscal 2001; Camp et al. 2016), which is probably their center of origin (Santini and Polacco 2006; Litsios et al. 2014b). In the Madang region (Papua New Guinea), nine species of anemonefish can be found in sympatry. Such coexistence is explained by niche differentiation, species coexisting through resource partitioning by using different host anemone species and/or habitat (e.g. depth, localization in the reef). They can even 

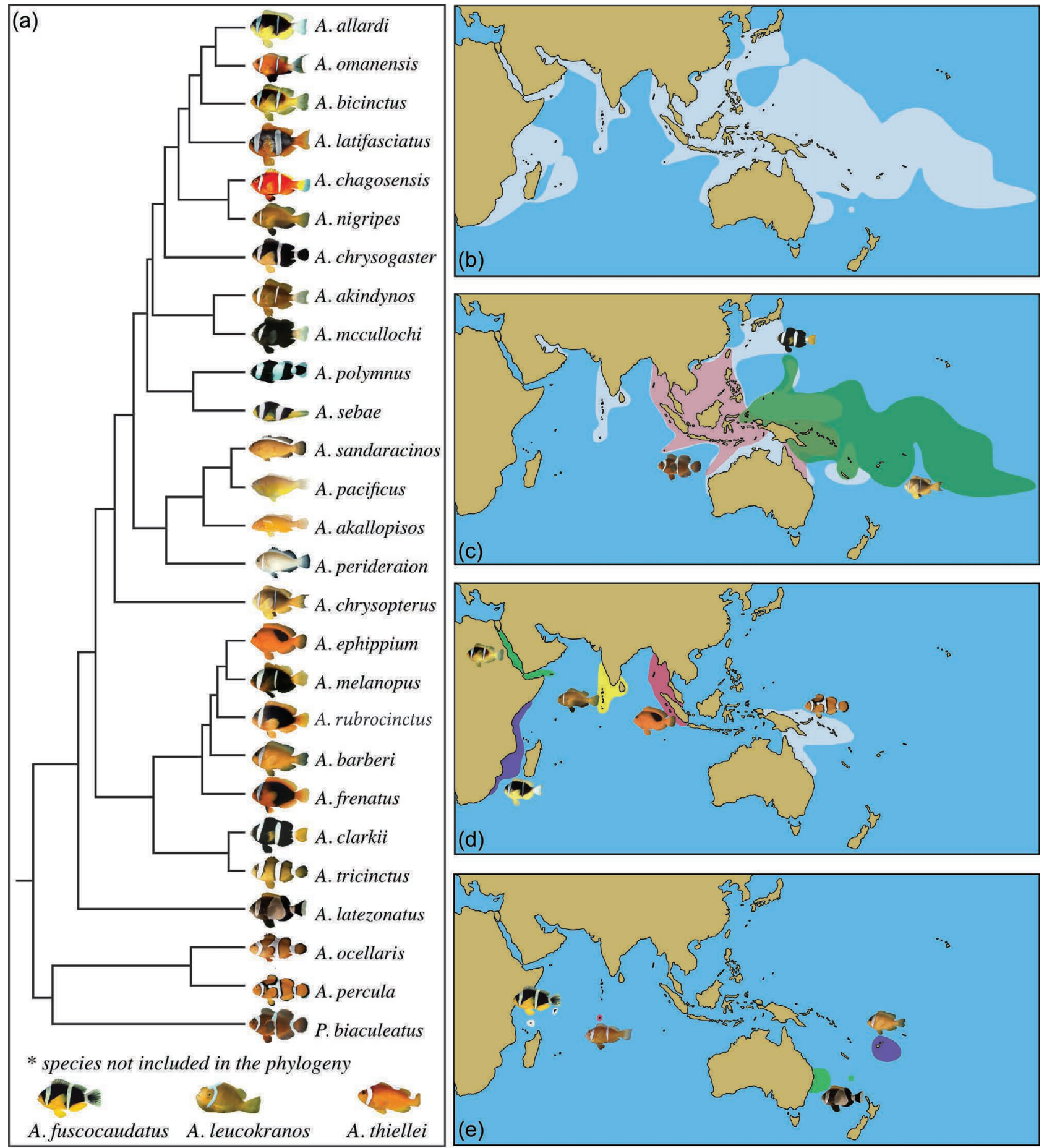

FIGURE 24.2 Phylogenetic relationship and geographic distribution of anemonefishes. Phylogenetic tree of 27 anemonefish species. Three species could not be included in the tree because they are either rare (A. fuscocaudatus) or hybrid species (A. leucokranos and $A$. thiellei) (a) Anemonefishes are distributed across the Indo-Pacific Ocean (b), with some species being widespread, such as $A$. chryosopterus, A. clarkii and P. biaculeatus (c); regional, such as A. allardi, A. bicinctus, A. ephippium, A. nigripes and A. percula (d); or restricted to specific areas, such as A. barberi, A. chagosensis, A. fuscocaudatus and A. latezonatus (e). (Adapted from the published work of Litsios et al. 2014b; Rolland et al. 2018.)

coexist in the same anemone (Figure 24.1b) by partitioning space in it (Elliott and Mariscal 2001; Camp et al. 2016; Hayashi et al. 2018). Anemonefishes can also be found in the Red Sea, the southwest coasts of Africa, the Maldives,
French Polynesia and as far north as the southeast coast of Japan, where the warm Kuroshio current carrying tropical waters provide them adequate conditions (Moyer 1976; Fautin and Allen 1992; Fautin and Allen 1997). According 
to their evolutionary history, anemonefishes first spread from the Coral Triangle and then colonized the Indian and central Pacific Oceans, where they diversified around four million years ago (Mya), leading to their present distribution and diversity (Litsios et al. 2014b). In accordance with this model, farther from the coral triangle, species richness declines (Camp et al. 2016). While six species can still be found in sympatry in Okinawa (Japan) (Hayashi et al. 2018) or Lizard Island (Great Barrier Reef), only one is living in the Red Sea or French Polynesia (Allen 1974; Fautin 1988; Elliott and Mariscal 2001). Anemonefishes are not found in some Pacific islands such as the Hawaiian Islands, Johnston Atoll and the Marquesas (Randall 1955), nor on the coast of Central and South America or the Atlantic. This pattern of distribution is common to many Indo-Pacific species, which are unable to disperse past the East Pacific Barrier (Briggs 1961; Robertson et al. 2004). Since anemonefishes are obligate symbionts, their distribution is strictly dependent on their Actinian host's distribution and specific habitat requirements. Due to their endosymbiotic zooxanthellae host, sea anemones are restricted to the photic zone $(\leq 200$ $\mathrm{m})$, and therefore anemonefishes are mainly found in clear shallow waters, usually no deeper than $50 \mathrm{~m}$.

\subsection{LIFE CYCLE}

Anemonefishes exhibit the classical bi-partite life cycle of most reef fish, which is composed of a pelagic dispersive larval phase followed by a demersal juvenile and adult phase (Leis 1991) (Figure 24.3). However, their peculiar lifestyle distinguishes them from other species.

Anemonefishes live in socially well-structured colonies composed of a dominant breeding pair and several immature individuals (Figure 24.1a). A sized-based dominance hierarchy structures each colony; the largest fish is a dominant female, which defends the colony, and the second largest is a sub-dominant male taking care of the demersal eggs (Olivotto and Geffroy 2017). This monogamous pair is surrounded by smaller, sexually immature individuals, ranked by size, the smallest (youngest recruit) being at the bottom of the hierarchy (Fautin and Allen 1992; Buston 2003a; Iwata et al. 2012; Casas et al. 2016; Olivotto and Geffroy 2017). Anemonefishes have been described as protandrous sequential hermaphrodites, and the sex change from functional male to female is size dependent and/or socially mediated (Fricke and Fricke 1977). When the female disappears from the group, the male changes sex, and the third-ranked fish inherits the male breeding position and territory, thus forming a new monogamous pair (Buston 2004b; Mitchell 2005). Therefore, the size hierarchy represents a queue to attain dominant status and reproduction, individuals only ascending in rank when a higher-ranked individual disappears (Rueger et al. 2018).

Reproduction occurs all year around (except in extreme parts of their distribution range, where reproduction stops during winter), every two to three weeks, usually a week before or after a full moon (Seymour et al. 2018). The breeding couple adopts a specific behavior, which varies among species but generally includes male and female swimming close to each other and touching bellies. This "parade" is initiated by the female, which subsequently lays between 100 and 1,000 eggs, depending on species and conditions, in a roughly circular patch that are immediately fertilized by the male (Allen 1974; Buston and Elith 2011). Eggs are attached to a rock in the direct vicinity of the host sea anemone. This makes anemonefish benthic spawners, unlike most coral reef fish that spawn in the open ocean.

Embryonic development lasts between seven and ten days, during which mainly the male takes care of the eggs by fanning and mouthing them, removing dead ones (which are eaten) and keeping the nest clean (Allen 1974). Hatching occurs just after dusk, and larvae disperse in the open ocean for up to 15 days. The embryonic phase of anemonefish development is rather long compared to other fish species even when compared to other Pomacentridae (e.g. one day for the night sergeant Abudefduftaurus, three days for the threespot dascyllus D. trimaculatus) (Kavanagh and Alford 2003). Therefore, hatching larvae already have the ability to swim, feed and catch prey merely hours after hatching (Putra et al. 2012). This makes anemonefish larval development one of the shortest known for coral reef fishes (for instance, most pomacentrids have a pelagic larval duration [PLD] that lasts approximately 25 days) (Victor and Wellington 2000; Berumen et al. 2010).

After this dispersive pelagic phase, larvae metamorphose into juvenile individuals. Metamorphosis is a crucial developmental step mediated by thyroid hormones, during which morphological, physiological, behavioral and ecological changes lead to the loss of larval attributes (Laudet 2011). At this time, juveniles look like small adults and leave the open ocean to enter the reef, a process known as recruitment (Figure 24.3). More details on embryonic and larval development as well as on metamorphosis are provided in Section 24.4. Once recruited to the reef, juveniles actively search for an adequate sea anemone using environmental cues and their sensory abilities (Leis et al. 2011; Paris et al. 2013; Barth et al. 2015) to settle and establish the fascinating symbiosis that is so typical of anemonefishes.

The long-term association between anemonefishes and their sea anemones is considered a mutualistic relationship, as the sea anemone provides protection to the anemonefishes, which in turn provide nitrogen and carbon to their host and its endosymbiotic zooxanthellae (playing an important role in their nutrition) (Cleveland et al. 2011), provide protection against predators (mainly butterflyfishes) (Fautin 1991) and reduce hypoxia through aeration-like behavior (Herbert et al. 2017).

This association has always intrigued scientists for two main reasons. First, there is a complex species specificity of this mutualistic relationship, probably related to the toxicity levels of the hosts (Litsios et al. 2012b; Nedosyko et al. 2014; Marcionetti et al. 2019). A few anemonefish species live only in one sea anemone species, such as A. sebae and $P$. biaculatus (i.e. specialists). On the contrary, other species may have two or even ten possible hosts such as A. ocellaris, 


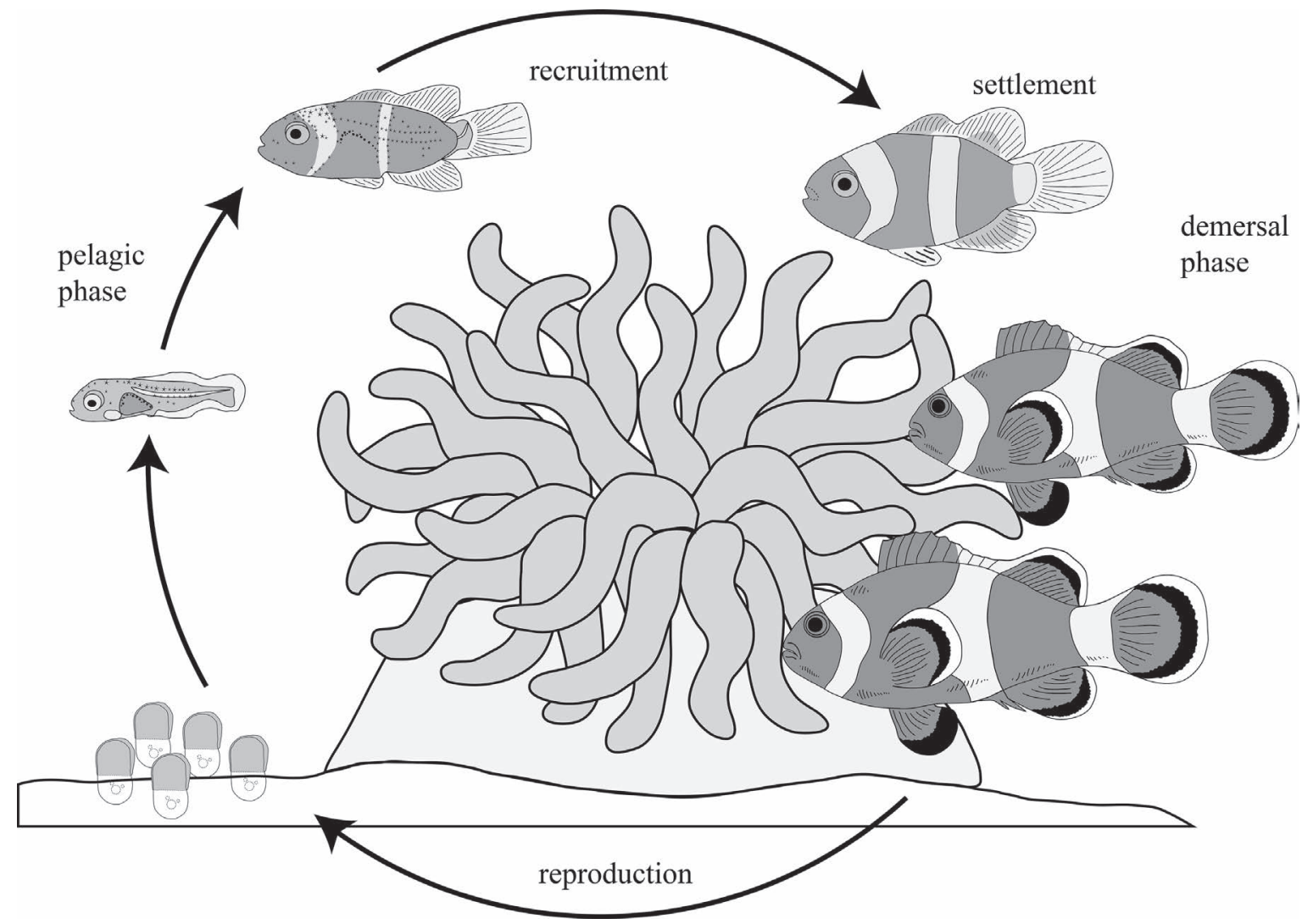

FIGURE 24.3 Anemonefish life cycle. Eggs are laid on the substrate close to the host sea anemone. After hatching, the pelagic larvae disperse in the open ocean. Recruitment to the reef coincides with metamorphosis from larvae to juveniles, which then settle into a sea anemone.

A. bicinctus, A clarkii and A. perideraion (i.e. generalists) (Fautin and Allen 1997) (Table 24.1).

Second, anemonefishes are able to live unharmed inside the tentacles of their host, which are known to discharge stinging cells called nematocysts (Mebs 2009). Two main hypotheses have been formulated to explain this ability. The first one suggests that anemonefishes coat themselves with sea anemone mucus, which is therefore used as a chemical camouflage (Fautin 1991; Scott 2008). This is achieved during an acclimation process that corresponds to a series of behaviors during which anemonefishes carefully enter their hosts (Schlichter 1968). First, they kiss the tentacles, then touch them with their pectoral fins and finally scrub their entire body against the tentacles. This behavior has been observed in several species, but not all, and it also seems different depending on the sea anemone species. Surprisingly, A. clarkii needs to acclimate when entering in Entacmea quadricolor but not when entering the more toxic Stichodactyla haddoni (Lubbock 1981; Elliott and Mariscal 1997; Mebs 2009). The second hypothesis suggests that anemonefishes are protected from sea anemone stinging by their own mucus that either prevents nematocyst discharge or protects the fish from the consequence of the discharge. Indeed, it has been shown that $A$. ocellaris lacks $\mathrm{N}$-acetylneuraminic acid in its mucus, which is normally detected by sea anemone tentacles to discharge stinging cells (Abdullah and Saad 2015). All these studies suggest that the mucus of both partners is the key to understanding how anemonefishes are able to live in sea anemones without being harmed. Moreover, it has recently been demonstrated that changes in the microbial composition are occurring in both partners during initiation of the symbiosis, suggesting a potential role of bacterial communities in the establishment of this relationship (Pratte et al. 2018; Roux et al. 2019a).

After settlement, anemonefishes integrate into the colony hierarchy, queuing for breeding positions. Why and how anemonefishes engage in such a social system is starting to be understood thanks to extensive work on A. percula colonies and may have a great contribution to the understanding of complex societies. Buston and collaborators have shown that members of a colony are not composed of close relatives (2007) and that non-breeders don't provide alloparental care, their presence having neither a positive or negative effect on the dominant pair's breeding success (Buston 2004a). Nonbreeders can adjust their size and growth rate in order to maintain a clear size difference with respect to individuals of higher social rank so that conflicts are limited, thereby reducing the risk of eviction and the potential cost to the breeding dominant pair (Buston 2003a). Consequently, there seem to be no direct benefits of living in such social groups. However, withholding reproduction by staying small and not contesting to remain part of the colony might represent a better option than either leaving the host anemone to breed elsewhere (because of predation risk) or contesting for breeding 
TABLE 24.1

Summary of host anemone specificity among all 30 members of the clade (A. - Amphiprion, P. - Premnas).

\begin{tabular}{|c|c|c|c|c|c|c|c|c|c|c|}
\hline & C. adh & E. qua & H. aur & H. cri & H. mag & H. mal & M. dor & S. gig & S. had & S. mer \\
\hline \multicolumn{11}{|l|}{ A. akallopisos } \\
\hline \multicolumn{11}{|l|}{ A. akindynos } \\
\hline \multicolumn{11}{|l|}{ A. allardi } \\
\hline \multicolumn{11}{|l|}{ A. barberi } \\
\hline \multicolumn{11}{|l|}{ A. bicinctus } \\
\hline \multicolumn{11}{|l|}{ A. chagosensis } \\
\hline \multicolumn{11}{|c|}{ A. chrysogaster } \\
\hline \multicolumn{11}{|c|}{ A. chrysopterus } \\
\hline \multicolumn{11}{|l|}{ A. clarkii } \\
\hline \multicolumn{11}{|l|}{ A. ephippium } \\
\hline \multicolumn{11}{|l|}{ A. frenatus } \\
\hline \multicolumn{11}{|c|}{ A. fuscocaudatus } \\
\hline \multicolumn{11}{|l|}{ A. latezonatus } \\
\hline \multicolumn{11}{|l|}{ A. latifasciatus } \\
\hline \multicolumn{11}{|l|}{ A. leucokranos } \\
\hline \multicolumn{11}{|l|}{ A. mccullochi } \\
\hline \multicolumn{11}{|l|}{ A. melanopus } \\
\hline \multicolumn{11}{|l|}{ A. nigripes } \\
\hline \multicolumn{11}{|l|}{ A. ocellaris } \\
\hline \multicolumn{11}{|l|}{ A. omanensis } \\
\hline \multicolumn{11}{|l|}{ A. pacificus } \\
\hline \multicolumn{11}{|l|}{ A. percula } \\
\hline \multicolumn{11}{|l|}{ A. perideraion } \\
\hline \multicolumn{11}{|l|}{ A. polymnus } \\
\hline \multicolumn{11}{|c|}{ A. rubrocinctus } \\
\hline \multicolumn{11}{|c|}{ A. sandaracinos } \\
\hline \multicolumn{11}{|l|}{ A. sebae } \\
\hline \multicolumn{11}{|l|}{ A. thiellei } \\
\hline A. tricinctus & & & & & & & & & & \\
\hline P. biaculeatus & & & & & & & & & & \\
\hline
\end{tabular}

* C. adh-Cryptodendrum adhaesivum, E. qua - Entacmaea quadricolor, H. aur-Heteractis aurora, H. cri - Heteractis crispa, H. mag - Heteractis magnifica, H. mal-Heteractis malu, M. dor-Macrodactyla doreensis, S. gig-Stichodactyla gigantea, S. had-Stichodactyla haddoni, S. mer-Stichodactyla mertensii

(because of the risk of being evicted or even killed; Buston 2003b; Rueger et al. 2018). Moreover, long-term benefits can come from staying in the colony, as subordinates will inherit the territory in which they reside after the death of breeding individuals (Buston 2004b).

Once they are finally able to reach the highest hierarchical rank, anemonefishes have to undergo a protandrous sex change (from functional male to functional female). Hermaphroditism is widely found in at least 27 teleost families, including Pomacentridae. Indeed, among vertebrates, teleost fish exhibit the greatest diversity in sex determination in relation to a remarkable plasticity of gonadal development and sexual expression (Munday et al. 2006; Liu et al. 2017; Ortega-Recalde et al. 2020).

However, even though the social hierarchy of anemonefishes has been well described for several species, the internal mechanisms at play during protandrous sex change are still poorly understood. Nonetheless, one of the main 
advantages of anemonefishes as model organisms is that sex change can be experimentally induced, both in field and laboratory conditions, by simply removing the dominant female. It is thus possible to study the molecular and physiological mechanisms governing sex change by following the dominant male during its transition into a functional female.

Histological analysis of gonads revealed that juveniles develop bisexual gonads, otherwise known as ovotestis, possessing both male and female tissues which are topographically distinct but not separated (Kobayashi et al. 2013; Todd et al. 2016; Gemmell et al. 2019). Once sexual maturity is reached, the ovotestis of the reproducing male exhibits a functional male territory, where spermatogenesis occurs, and an immature female territory (Kobayashi et al. 2010). During protandrous sex change, oogenesis occurs in the developing female area of the ovotestis, while the male territory progressively disappears (Casas et al. 2016). This histological scenario of gonadal protandrous transition is the same for all species of anemonefish studied so far (Godwin 1994; Kobayashi et al. 2013; Casas et al. 2016). Studies have reported that cellular changes within the ovotestis are subjected to endocrine control during sex change (Kobayashi et al. 2010; Miura et al. 2013). Like in other sequential hermaphroditic fish, the gonadal sex change is accompanied by major shifts in plasma levels of sex steroid hormones, mainly characterized by a decrease of 11-ketotestosterone levels and a subsequent 17ß-estradiol increase (Godwin and Thomas 1993; Miura et al. 2013). Even though observed experimentally, the upstream mechanisms controlling the shift in sex steroid secretion still remain poorly understood. It has been suggested that the crosstalk between the hypotholamo-pituitary-gonadal (HPG) and hypothalamo-pituitary-interenal (HPI) axes plays a central role in the neuroendocrine regulation of protandrous sex change in anemonefishes (Godwin et al. 1996; Lamm et al. 2015). The association between stress and hermaphroditism was first described in A. melanopus, in which a peak of serum cortisol levels were observed during later sex change stages (Godwin and Thomas 1993; Goikoetxea et al. 2017; Geffroy and Douhard 2019).

Natural mortality of adult anemonefishes is very low compared to other coral reef fishes, which is most probably due to them being protected from predators by living within their host anemone. Mortality rate is not affected by environmental (e.g. reef, depth, anemone diameter) or demographic (e.g. number of individuals, density and standard length) parameters (Buston 2003b). However, it differs according to the hierarchical rank occupied by the fish. Since low-ranked individuals can be evicted from the anemone and thus undergo greater predatory pressure, juveniles suffer higher mortality than dominant individuals (Buston 2003b; Salles et al. 2015). Standard evolutionary theories of aging (i.e. mutation accumulation, antagonistic pleiotropy and disposable soma theory) predict that low extrinsic mortality leads to the evolution of slow senescence and an extended lifespan (Medawar 1952; Williams 1957; Kirkwood 1977). Anemonefishes are a great example confirming these theories, with some species having been observed to live over 20 years (Sahm et al. 2019), while predictions estimate a lifespan of up to 30 years (Buston and García 2007). Such longevity is exceptional for small fishes and at least twice the estimated longevity for other pomacentrids (Buston and García 2007; Sahm et al. 2019).

\subsection{DEVELOPMENT}

Anemonefish eggs are capsule shaped, and their size varies depending on the species, with a length from $1.3-1.5 \mathrm{~mm}$ (A. ephippium) to $2.4-2.6 \mathrm{~mm}$ (A. nigripes) and a width from $0.53-0.72 \mathrm{~mm}$ (A. ephippium) to $1.0-1.2 \mathrm{~mm}$ (A. percula) (Dhaneesh et al. 2009; Anil et al. 2012; Krishna 2018). The developing embryo is separated from a large amount of yolk (i.e. polylecithal, telolecithal egg), which is colored yellow to orange or even red (due to the presence of carotenoids), similar to the parent coloration. The side of the egg that is attached to the substrate (via a glutinous substance and/ or threads) has consistently been recognized as the animal pole. Fertilization activates the egg and is characterized by cytoplasmic movements, which result in the formation of a dome-shaped blastodisc (Yasir and Qin 2007; Thomas et al. 2015; Krishna 2018). The chorion is transparent and leaves a narrow perivitelline space. Embryonic development usually lasts between six and eight days, depending on species and temperature. Major developmental changes will be described for all species, as they are very similar to each other, only differing in the exact timing. The following species and literature were compared for this: A. akallopisos (Dhaneesh et al. 2012), A. bicinctus (Shabana and Helal 2006), A. ephippium (Krishna 2018), A. frenatus (Ghosh et al. 2009), A. melanopus (Green 2004), A. nigripes (Anil et al. 2012), A. ocellaris (Liew et al. 2006, Yasir and Qin 2007, Madhu et al. 2012, Salis et al.), A. percula (Dhaneesh et al. 2009), A. polymnus (Rattanayuvakorn et al. 2005) and A. sebae (Thomas et al. 2015; Gunasekaran et al. 2017). To avoid disruption, these studies will not be cited again in the following descriptions.

\subsubsection{Embryonic Stage 1: Eariy Cleavages (Figure 24.4A)}

This stage comprises four synchronous division cycles that lead from a zygote to a 16-cell stage. All blastomeres of a given cell stage are of equal size. Cleavages are meroblastic (partial cleavage) and discoidal (cleavage furrows do not penetrate the yolk). The yolk exhibits prominent fat/oil globules throughout these cleavages.

\subsubsection{Embryonic Stage 2: Late Cleavages (Figure 24.4B)}

This stage comprises the division of the 16-cell stage until the start of gastrulation. All blastomeres are of equal size, partially overlapping each other as they arrange themselves into several layers (sphere shape) before they start to spread. The fat/oil globules decrease in number and size and are typically located toward the vegetal pole. 
(a)

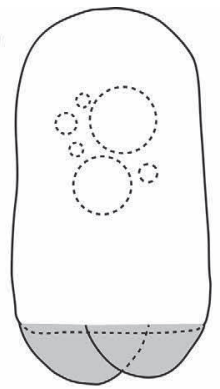

(c)

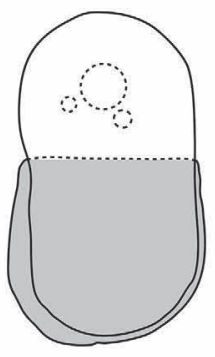

(e)

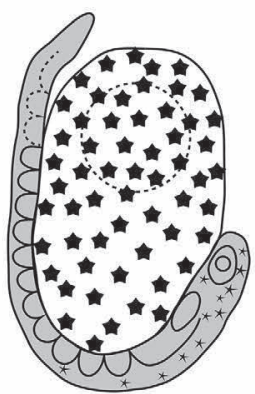

(g)

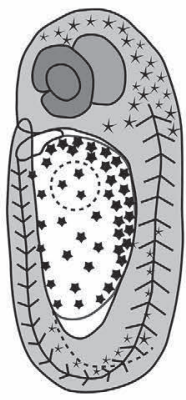

(b)

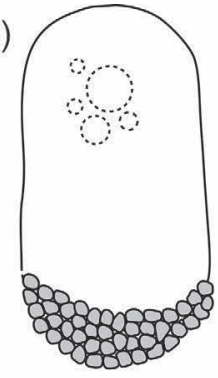

(d)

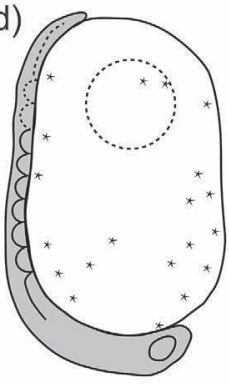

(f)

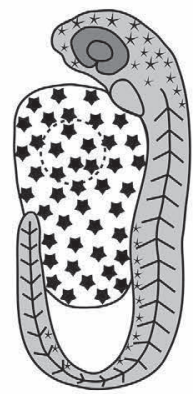

(h)

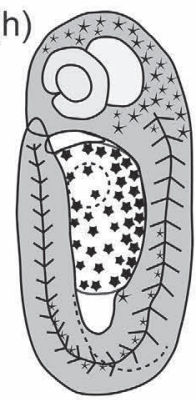

(i)

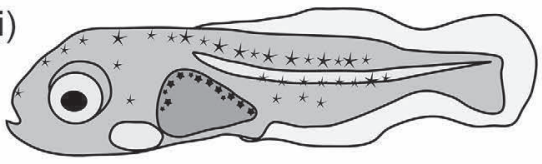

(k)

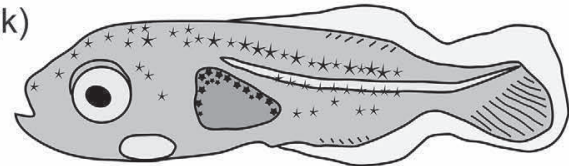

(l)

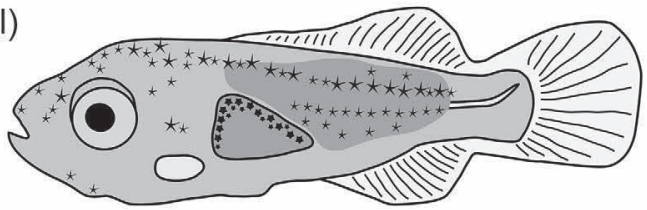

(m)

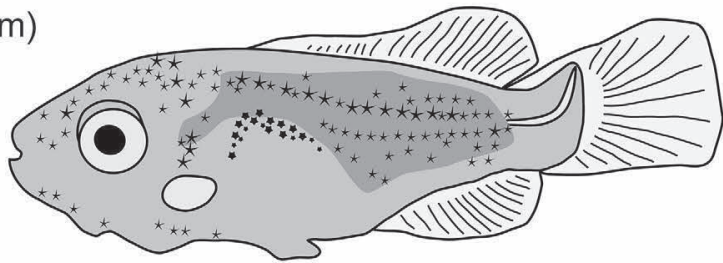

(n)

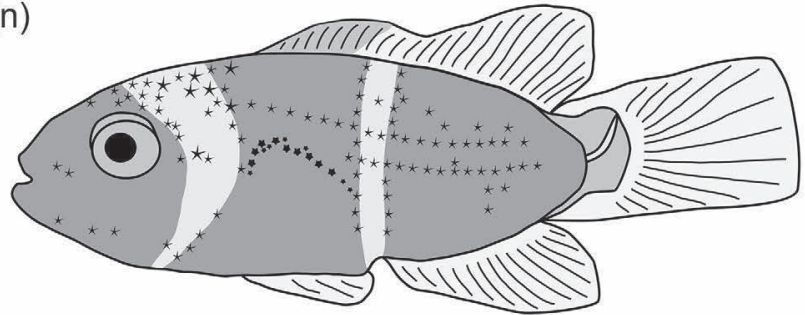

(o)

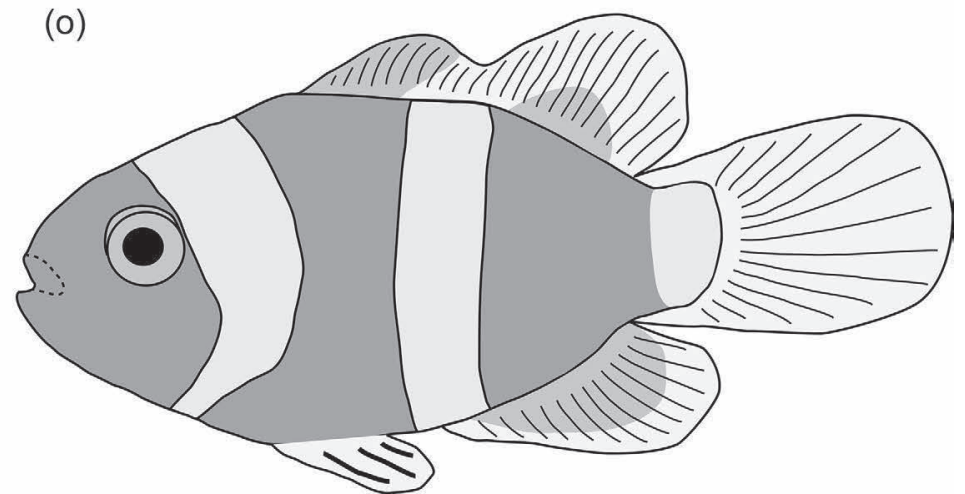

FIGURE 24.4 Embryonic ( $\mathrm{a}-\mathrm{h})$ and larval (i-o) development of anemonefishes. The schematic drawings of embryonic stages are representative for all anemonefish species and do not refer to a single species, whereas A. ocellaris was used as representative for larval schematics (according to Roux et al. 2019b).

\subsubsection{Embryonic Stage 3: Gastrulation (FIGURe 24.4C)}

This stage comprises gastrulation, the formation of the three germ layers: ectoderm, mesoderm and endoderm. During the first step, epiboly, blastomeres flatten, move and extend toward the vegetal pole, covering the underlying yolk. Terms like $50 \%$ or $75 \%$ epiboly describe how much yolk has been covered by the blastoderm (i.e. the connective sheet of blastomeres). Formation of the embryonic shield, the future embryo, is achieved by a local thickening of blastomeres during $30-75 \%$ epiboly. 


\subsubsection{Embryonic Stage 4: Cephalization and Somite Development (Figure 24.4d)}

The head, including optic buds (located at the animal pole), as well as neural ectoderm, is formed. The tail bud begins to develop later on. Overall, this stage marks the beginning of organogenesis and metamerization. The first appearance of paired somites occurs before $100 \%$ epiboly is reached (around $60-80 \%$ epiboly). Stellate melanophores begin to cover the yolk.

\subsubsection{Embryonic Stage 5: Turn- Over (Figure 24.4E)}

The entire body of the embryo is covered with few melanophores, particularly abundant in the head region. The head is clearly distinguishable, and the brain has differentiated into three parts: the prosencephalon, mesencephalon and rhombencephalon. Primitive optic buds/vesicles have formed, with subsequent induction of eye formation (eye cup, lens and cornea). Somitogenesis (trunk segmentation) is finished at the end of this stage. The body is transparent due to the absence of muscular structure at beginning, but later on, myotomes are recognizable. The embryo completely turns itself (body reversal by positioning the head toward the vegetal pole) while the tip of the tail is still attached to the yolk sac. This is a critical step for further development to proceed. The body is attached to the yolk sac, while the tail detaches from the yolk toward the end of this stage and exhibits increasing tail movements. A tubular, pink-colored heart has been differentiated and begins to beat.

\subsubsection{Embryonic Stage 6: Blood FORMATION (Figure 24.4F)}

The head and tail of the embryo have distinctly separated from the yolk, which is reduced in its volume. The body length has increased distinctly. Transparent (later a light shade of pink) spherical blood cells and subsequently blood circulation can be observed. Pigmentation is prominent in the head, especially in the large eyes displaying brownish pigments, but less in the tail region. Skeletal muscles and myotomes become clearly visible.

\subsubsection{Embryonic Stage 7: Remaining Organ and Fin Development (Figure 24.4G)}

The head occupies one-third of the capsule space and has salient eyes with brown melanin pigmentation. The size of the entire embryo has increased substantially, with the tail reaching the posterior part of the eyes, and it displays continuous movement. The yolk sac becomes quite small, and yellow pigments start to appear on the trunk. Branchial arches with ventilating gills and opercula, a looped alimentary tract and jaws have developed. The fin folds have developed and are clearly visible.

\subsubsection{Embryonic Stage 8: Hatching (Figure 24.4h)}

A hindgut has formed, and the embryo fully occupies the capsule. The spinal cord is not flexed. The eyes are turning and silver shining (eyeshine from the tapetum). The embryo tries to hatch out: vigorous movements of the tail rupture an area close to the base of the eggshell (where the egg is attached to the substrate). The hatchlings emerge tail first, which usually takes place after sunset in complete darkness.

A relatively short larval development follows hatching and precedes metamorphosis. Even though developmental time frames for larvae are more variable than for embryos, the following studies have been combined to describe larval development and metamorphosis for anemonefishes in general: A. ephippium (Krishna 2018), A. frenatus (Putra et al. 2012), A. nigripes (Anil et al. 2012), A. ocellaris (Madhu et al. 2012; Roux et al. 2019b), A. perideraion (Salis et al. 2018a) and A. sebae (Gunasekaran et al. 2017).

\subsubsection{Larval Stage 1: Preflexion of the Notochord (Figure 24.4I)}

The larvae are mainly transparent, with some melanophores and xanthophores scattered over the head and body. Additionally, one or two horizontal lines of melanophores are present on the trunk, along the ventral midline. The embryonic fin folds remain undifferentiated and transparent. The notochord is still straight, in preflexion. Larvae are able to feed on live prey soon after hatching and process the food in a short, straight alimentary canal with the anus located in the middle of the body length. Stomach, midgut and hindgut are distinct, and the liver and pancreas are differentiated. The larvae display phototropic behavior and swim at the top of the water column.

\subsubsection{Larval Stage 2: Flexion of the Notochord (Figure 24.4K)}

The embryonic fin folds start to differentiate into the caudal, dorsal and anal fins, which exhibit first signs of soft rays. The notochord begins to flex by bending dorsally.

\subsubsection{Larval Stage 3: Postflexion of the Notochord (Figure 24.4L)}

The embryonic fin folds have completely differentiated into caudal, dorsal and anal fins. Both anal and dorsal fins exhibit the complete set of soft rays and spines that start to appear in a posterior-anterior gradient. The pelvic fins begin to differentiate. The notochord is in postflexion, resulting in a vertical position of the hypural bones. There are no major changes in pigmentation pattern or swimming behavior. 


\subsubsection{Larval Stage 4: Pelvic Spine (Figure 24.4M)}

All fins, including the pelvic fins, are fully developed and possess all soft rays and spines. The numbers of melanophores and xanthophores scattered over the body are increasing. There is also a marked change in behavior, as larvae are not attracted to light anymore but swim close to the bottom. This can be considered the beginning of metamorphosis, which is accompanied by a shift from a pelagic to an epibenthic lifestyle.

\subsubsection{Larval Stage 5: Appearance of White Bands (Figure 24.4N)}

During this stage, pigmentation patterns changes drastically. On one hand, chromatophores (bearing pigments, which shift from yellow to orange/red) are beginning to spread into the dorsal and anal fins as well as the caudal peduncle and head. On the other hand, the horizontal lines of melanophores start to disappear. Instead, the vertical white bands on the head and, depending on the species, on the body ( $A$. ephippium, A. frenatus, A. ocellaris) start to emerge. They are transparent at the beginning but will adopt white color subsequently. Melanophores align at the border of the white bands. During metamorphosis, anemonefish larvae also undergo a rapid and extensive cranial remodeling that is linked with a change in preferred food items (Cooper et al. 2020). Furthermore, the shape of the body changes, and the width of the dorso-ventral axis increases, resulting in a more oval shape.

\subsubsection{Larval Stage 6: Maturation of Adult Color Pattern (Figure 24.4o)}

Although the final maturation of the adult pigmentation is highly dependent on the anemonefish species, it is generally characterized by an increase in the thickness of the white bands. Pigmentation of the fins is completed during this stage in all species, with the caudal fin being the last to gain color. In A. ocellaris, for example, a third white band appears on the caudal peduncle after approximately $20 \mathrm{dph}$

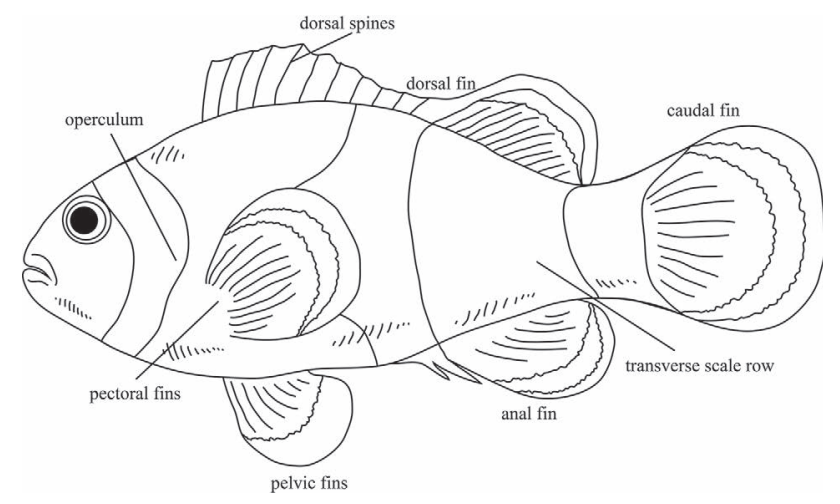

FIGURE 24.5 Schematic drawing of A. ocellaris showing external anatomical features. (days post-hatching), resulting in an adult that possesses three white bands. In A. ephippium, on the other hand, both the head and body white bands increase in thickness before they start to disappear. It has been described that this process starts with the middle portion of the body band at 50-55 dph and then slowly regresses toward the dorsal and ventral sites (completion by $160 \mathrm{dph}$ ). After that, the head band starts to disappear at approximately $240 \mathrm{dph}$ and is completely gone by 300-310 dph. Similarly, larvae of A. frenatus exhibit a transient white band on the body at $20 \mathrm{dph}$, which subsequently disappears.

\subsection{ANATOMY}

The following anatomical features can be used to distinguish members of the Amphiprioninae (Figure 24.5) from the remainder of the pomacentrids (Allen 1974; Nelson et al. 2016):

1 Nine to 11 dorsal spines

2 Suborbital, preopercle, opercle and interopercle bones with serrated or spinous margins and/or sculptured with radiating striae

3 Usually more than 50 transverse scale rows

Many tribe members also share the following features:

1 Teeth are uniserial and usually conical

2 Snout is mostly naked

3 Color pattern consists of one to three whitish bands on a darker background, which can be of various shades of orange, red, brown or black [exceptions are (i) A. akallopisos, A. ephippium, and A. pacificus, which do not have any bands, and (ii) $A$. perideraion and A. sandaracinos, which exhibit a dorsal stripe]

Anemonefishes are small sized $(5-15 \mathrm{~cm})$, and their body is oval and compressed (laterally thin) with a well-defined head and tail. As vertebrates, they possess all the characteristic organs and organ systems that specify this clade, such as a notochord, which develops into a vertebral column, gill arches, and neural crest cells. As representatives of the ray-finned fishes (Actinopterygii), the external anatomy is characterized by the presence of fin rays in the paired and unpaired fins, an operculum, a lateral line system and overlapping scales (Figure 24.5). Furthermore, they have specialized internal organs, such as three pairs of gill arches and a swim bladder.

The brains of anemonefishes exhibit typical features of teleostean brains; among others, these are: (i) large rhombencephalon; (ii) large unpaired cerebellum; (iii) two pronounced tectal halves located dorsal to the midbrain tegmentum and diencephalon; (iv) large, paired hypothalamic inferior lobe bulging out in the ventral brain surface; and (v) relatively small, everted telencephalon and relatively large olfactory bulbs (Nieuwenhuys et al. 1998). Furthermore, the visual system of $A$. akindynos was studied in high detail by 
Sieb and colleagues (2019), who showed that retinal cones are arranged in a repetitive pattern, with four double cones surrounding a single cone.

All species of anemonefishes can produce and hear sounds, mainly composed of chirps and short and long pops (Parmentier et al. 2005; Parmentier et al. 2009). Pops are usually displayed as an aggressive, agonistic behavior against both conspecifics and heterospecifics. On the other hand, courtship sounds are more complex and differ in the number of pulses, pulse duration and dominant frequency. Sounds convey information about the size of the individual producing it, therefore implying the social rank of the emitter (Colleye et al. 2009). Sounds are produced by a series of cranial-focal interactions (Parmentier et al. 2007). First, the hyoid bar is lowered rapidly. Second, the sonic ligament, which connects the hyoid bar and internal parts of the mandible, is stretched and therefore forces the mandible to turn around its articulation, which in turn is closing the mouth. Third, the sound itself is made by collisions of the jaw teeth, with the jaw potentially acting as an amplifier. The sonic ligament represents a novel adaptation of the skeletal repertoire of anemonefish and other damselfish.

\subsection{GENOMIC DATA}

Actinopterygian fishes have a complex genomic history, and anemonefishes are of course no exception. In the 1970s, Susumu Ohno highlighted the importance of gene duplications as an important evolutionary mechanism that allows the creation of novelties during evolution (Ohno 1970). He further hypothesized that two rounds (2R) of whole genome duplications (WGDs) occurred early during vertebrate evolution. This was a controversial claim at the time, but it is now clear that there were effectively two genome duplications at the base of vertebrates. This is the famous " $2 \mathrm{R}$ hypothesis", which is now largely accepted even if there are still many discussions about the precise timing and even magnitude of these duplications (reviewed in Onimaru and Kuraku 2018).

In actinopterygians, the situation is even more complex, as a third genome duplication occurred at the base of the group (Meyer and Schartl 1999; Jaillon et al. 2004). This WGD is estimated to have taken place ca. 300 Mya and is often called the "teleost-specific genome duplication" or "Ts3R" (reviewed in Glasauer and Neuhauss 2014). Within teleosts, there were several more recent lineage-specific events, such as a fourth round of WGD in salmonids ca. 100 Mya (Berthelot et al. 2014) or in the lineage of carps within cyprinids ca. 5-10 Mya ( $\mathrm{Li}$ et al. 2015). Anemonefishes are at the typical level of teleost fishes for which three WGDs have occurred: the two at the base of vertebrates, plus the one at the base of teleost fishes.

These events provide a higher complexity in terms of gene numbers in teleost fishes than in other vertebrate lineages such as birds or mammals. This may also be linked to the great number of species in teleosts as well as their extraordinary phenotypic diversity, although the link between WGDs and species diversity is still a matter of debate (Glasauer and Neuhauss 2014; Onimaru and Kuraku 2018).

The so-called DDC model (duplication-degenerationcomplementation) predicts three possible outcomes following duplication of a gene: (i) non-functionalization (i.e. the loss of one of the duplicates), (ii) neo-functionalization (i.e. one of the copies retains the ancestral role, while the other duplicate assumes a novel functionality) or (iii) subfunctionalization (i.e. both duplicates assume a part of the function of the single ancestral gene). While the model predicts that the most likely outcome following duplication of a gene is the loss of one of the duplicates (i.e. non-functionalization), there are now several examples of neo-functionalization and sub-functionalization of duplicated genes (e.g. Kawaguchi et al. 2013 for stickleback hatching enzymes or Bertrand et al. 2004 for nuclear receptors in zebrafish).

This complex evolutionary history must be taken into account when the genome data of anemonefishes is analyzed. The genomic era of anemonefish research started in 2018 with the first complete genome, that of A. ocellaris, which was generated using a mix of nanopore and Illumina sequencing (Tan et al. 2018). The coverage of this genome was low (11X), but this allowed the prediction of around 27,000 genes and a genome size of 800 to 900 million base pairs (Mbp). Then, the genomes of A. frenatus (Marcionetti et al. 2018) and A. percula (Lehmann et al. 2019) followed, as well as a high-density genetic map of A. bicinctus (Casas et al. 2018). Genome size and gene number have been estimated to be of ca. $850 \mathrm{Mbp}$ and 26,900 genes for A. frenatus and $908 \mathrm{Mb}$ and 26,600 genes for A. percula. The A. percula genome, determined by using single molecule real-time Pacific Bioscience technology, was of exceptional quality, as the authors also performed Hi-C-based chromosome contact mapping, resulting in a genome assembly into 24 chromosomes (reviewed in Hotaling and Kelley 2019). This was in accordance with previous karyotypic studies done on A. perideraion (Supiwong et al. 2015). This A. percula genome is now a unique resource for the whole community. Another major achievement was the genome assembly and annotation of nine species of anemonefish (A. akallopisos, A. bicinctus, A. melanopus, A. nigripes, A. ocellaris, A. perideraion, A. polymnus, A. sebae and P. biaculeatus) and a related damselfish outgroup, allowing for the first time insights into the genomics of anemonefish radiation and identification of genes that may be implicated in the symbiosis with sea anemones (Marcionetti et al. 2019). These datasets have already been used by independent authors to analyze specific gene sets such as peptidic hormones (Southey et al. 2020). Certainly, this is only the beginning of the anemonefish genomic era. We can anticipate that soon the genomes of all 30 known species of anemonefish will be available. Several genomes of distinct populations of anemonefishes are currently being sequenced, thus opening the way to population genomic analysis of these iconic fishes.

Complete genome sequences have been complemented by several transcriptomic data sets that started to tackle specific questions. A transcriptome of A. ocellaris post-embryonic 
development, spanning newly hatched larvae until settled juveniles, has been determined (Roux et al. in preparation). Another area of interest is the identification of genes related to the differently colored areas (white, orange and black) of A. ocellaris (Maytin et al. 2018; Salis et al. 2019a). This, combined with detailed pharmacological and microscopic analysis, has allowed researchers to determine that iridophores are responsible for the white color in this species but also to identify new iridophore and xanthophore genes in fish (Salis et al. 2019a, reviewed in Irion and Nüsslein-Volhard 2019; Patterson and Parichy 2019). Transcriptomic analysis has also been applied to the spectacular sex change abilities of anemonefishes. For example, a study of $A$. bicinctus from the Red Sea has revealed a complex genomic response in the brain and subsequently in the gonads with a prominent effect on genes implicated in steroidogenesis (Casas et al. 2016). Genes implicated in reproduction have also been studied in A. ocellaris (Yang et al. 2019).

Last, transcriptome analysis was used in the context of aging, as anemonefishes are known to have a long lifespan (Sahm et al. 2019). The authors have detected positively selected genes in A. clarkii and A. percula and tested if these genes were similar to those found in other models of aging such as mole rats or short-lived killifishes. They concluded that molecular convergence is likely to occur in the evolution of lifespan.

These examples are in fact the exhaustive list of genomic and transcriptomic studies done so far on anemonefishes. Due to low-cost high-throughput sequencing, it is likely that this will increase exponentially in the coming years as these fishes will be used more and more as experimental models which allow to link ecological, evolutionary and developmental studies.

\subsection{FUNCTIONAL APPROACHES: TOOLS FOR MOLECULAR AND CELLULAR ANALYSIS}

\subsubsection{HUSBANDRY}

Generally, the success of an emerging model species is linked to a feasible husbandry as well as the ease of obtaining samples. For marine teleosts, this can pose difficulties, as it might be difficult to achieve reproduction in captivity or to reliably locate them in the natural environment. Anemonefishes provide an excellent model for both scenarios. On the one hand, due to their close association with sea anemones, researchers are able to locate and re-locate anemonefishes with relative ease in the wild, enabling them to conduct long-term experiments with the same individuals. On the other hand, they are very well adapted for captive life, having been in the hobbyist trade for decades. For tropical marine fishes, anemonefishes are relatively tolerant to temperature $\left(24^{\circ} \mathrm{C}\right.$ to $\left.28^{\circ} \mathrm{C}\right)$ and salinity variations (25 to 40\%o) (Dhaneesh et al. 2012). Smaller species, like A. ocellaris, A. percula and A. sandaracinos, can be kept in 60-L tanks, while bigger species, such as $A$. clarkii, $A$. frenatus and $P$. biaculetatus, will need up to $200-\mathrm{L}$ tanks. In captivity, anemonefishes thrive without the addition of sea anemones and establish breeding pairs, which usually reproduce all year around. Both partners will participate in selection of an appropriate substrate and its cleaning, usually a terra cotta pot, ceramic tiles or even the glass walls. Egg clutch sizes vary greatly between and within species and depend on previous reproductive experience, nutrition and body size. A sufficient amount of eggs can be obtained for experimental purposes (up to 700-1,000 eggs) every 14-21 days. For experiments that require embryonic stages (such as micro-injection), the eggs can be scraped off substrate (for example, with a razor blade) and can be transferred to an egg tumbler or petri dishes for incubation. For experiments that require larval stages, the eggs remain with the parents until they are supposed to hatch (night of hatching). For hatching, they can be transferred into a separate aquarium by replacing the substrate with the attached eggs. Alternatively, if external water circulation can be interrupted, the larvae can hatch in the parent's aquarium and subsequently be transferred to a different aquarium by attracting them with a light source. This, however, is only advisable if there is no sea anemone in the same aquarium. Larvae can either be raised in small aquaria (20-30 L) or in 500-1,000-mL beakers (containing 1-20 larvae per beaker; Roux et al.). They are first fed with a mixture of micro algae and rotifers and later on Artemia nauplii. Juveniles are also fed with Artemia nauplii and either powdered food or food pellets (depending on size). The diet of adult fish is diverse and can be adjusted easily: Artemia, food pellets, chopped mussels, squid, shrimp and egg yolk, as well as vitamin supplements (Anil et al. 2012).

Several standard approaches have been successfully established in anemonefishes, and only a few will be highlighted here.

\subsubsection{In Situ Hybridization}

In situ hybridization is a very powerful tool to study temporal and spatial requirements of specific genes in their cellular context. In A. frenatus, embryonic mesodermal and neuroectodermal development has been followed by gene expression analysis of no tail ( $\mathrm{ntl}$ ) and sox3, respectively (Ghosh et al. 2009). Further, a comparative expression analysis of orthodenticle homeobox 2 (otx2) in the olfactory placode of larval A. percula indicates that this gene is required for olfactory responses to settlement cues (Veilleux et al. 2013). Moreover, in situ hybridization can validate results acquired employing alternative approaches, such as transcriptomics. For example, a recent study revealed several upregulated genes in the white skin of A. ocellaris, some of which could be confirmed via in situ hybridization on juvenile skin sections (Salis et al. 2019a). Fluorescent in situ hybridization (FISH) has also been successfully established in anemonefishes. In A. akindynos, it has been shown that long wavelength-sensitive (LWS)-related opsin genes are exclusively expressed in double cones, while short wavelength-sensitive (SWS)-related opsins are only expressed in the interspaced single cones (Stieb et al. 2019). 


\subsubsection{IMMUNOASSAY}

Commercial enzyme immunoassay (EIA) kits are available to analyze biochemical aspects of cells, such as hormones, neurotransmitters and second messenger molecules (such as cAMP). In 2010, Mills and colleagues validated two such kits for measuring 11-ketotestosterone and cortisol concentration, respectively, using blood plasma from A. chrysopterus and $A$. percula. They found that a minimum of $5-7 \mu \mathrm{L}$ blood plasma is sufficient to confidently estimate steroid hormone concentrations, which is especially valuable when working in the field. Other hormones, such as thyroid hormones, can be routinely measured using phenobarbital extraction and ELISA detection according to the method developed by Kawakami et al. (2008) and Holzer et al. (2017).

\subsubsection{Use of Drugs for Functional Experiments}

Pharmacological reagents/small molecules have been used widely in zebrafish, Danio rerio, and helped to broaden our understanding of zebrafish biology. To date, only few of them have been tested in anemonefishes, but they pose a great potential in a variety of fields. For example, it has been shown that the small molecule TAE 684 inhibits Alk and Ltk dependent iridophores in zebrafish (Rodrigues et al. 2012). In A. ocellaris, TAE 684 treatment of larvae results in juveniles without white bands, thus providing evidence that iridiophores are responsible for the white color of anemonefishes (Salis et al. 2019a). Furthermore, treatment with BMP inhibitors, such as dorsomorphin or DMH1, in early embryonic stages can result in dorsalization in zebrafish (Yu et al. 2008) and A. ocellaris (M. Klann personal observations) alike.

\subsubsection{Cell Culture}

So far, there is only one report on cell culture from anemonefish explants, even though this technique is extremely valuable for research projects focusing, for example, on virology, cytobiology and oncology/disease, but also for environmental toxicology/ecotoxicology or genetics/genomics. Patkaew and colleagues (2014) used A. ocellaris vertebrae explants to establish a corresponding primary culture. Four days after the initial implantation, fibroblastic cells could be seen, which then multiplied rapidly, reaching $70-80 \%$ confluence within four to five days. The fifth passage was preserved in liquid nitrogen for one month and subsequently assessed. The average viability after thawing and seeding has been reported with $80 \%$, with a $57 \%$ cell recovery and no obvious changes in cell morphology or growth pattern. Even though they do not give details, the authors also state that the employed explant method (without the use of enzymes) resulted in successful primary cultures from gills, skin and vertebrae from other anemonefishes.

\subsubsection{Genetic Markers}

Genetic markers, particularly microsatellites, have been developed and are now available for several anemonefish species.
They are widely used to study population genetics and have been used for example to investigate phylogeographic connectivity (Dohna et al. 2015), detect and monitor hybridization events (He et al. 2019; Gainsford et al. 2020), elucidate selfrecruitment of larval dispersal (Jones et al. 2005), estimate connectivity between marine protected areas (MPAs) (Planes et al. 2009) and even to determine the composition of social groups (Buston et al. 2007). A substantial number of population genetic and dynamic studies have been done on A. percula populations of Kimbe Bay (Papua New Guinea), with the notable construction of the first multigenerational pedigree for a marine fish population (Salles et al. 2016). Such genealogy provides an opportunity to investigate how maternal effect, environment or even philopatry can shape wild fish populations (Salles et al. 2020). Probably due to its localization in the diversity center of anemonefishes, Kimbe Bay represents a privileged study site for the investigation and testing of numerous ecological and evolutionary theories and mechanisms. For example, a recent study demonstrated that the combination of ecological and social pressure promotes the evolution of non-breeding strategies (Branconi et al. 2020). The integration of the generated data provides an invaluable cornerstone for future studies in the general field of ecology and evolution.

\subsection{CHALLENGING QUESTIONS, BOTH IN ACADEMIC AND APPLIED RESEARCH}

Anemonefishes are ideal emerging model systems to answer a wide range of questions in biology, including but not limited to conservation, host recognition, evolutionary mechanisms and biomedical research. Missing functional approaches are also discussed at the end of this section.

\subsubsection{Human Impact and Conservation}

Anemonefishes live in coral reefs, which are among the most threatened ecosystems. Many anthropogenic stressors act either globally or at a local scale: global warming, pollution, ocean acidification and deoxygenation, to name just a few (Altieri et al. 2017; Albright et al. 2018; Hughes et al. 2018; Porter et al. 2018). The effects of stressors on coral reef fishes can be studied at different levels, including growth, physiology, development, genetics, bioaccumulation and behavior. Information gained in any of these fields will provide a better understanding of the coral reef ecosystem and ultimately, its conservation. A few exploratory studies investigating the effect of anthropogenic stressors on anemonefishes have already been conducted, and some will be introduced subsequently. A chemical compound found in sunscreens acting as a UV filter (benzophenone-3) perturbed feeding and swimming behavior and led to a decrease of body weight even at small concentrations of $1 \mathrm{mg} / \mathrm{l}$ (Chen et al. 2018; Barone et al. 2019), whereas higher concentrations of $100 \mathrm{mg} / \mathrm{l}$ resulted in 25\% increased mortality rate (Barone et al. 2019). The direct impact of global warming (increased water temperature) on the physiology of anemonefishes has been investigated. The cellular stress responses (quantification of molecular 
biomarkers) of adults raised for one month at $26^{\circ} \mathrm{C}$ (control) or $30^{\circ} \mathrm{C}$ (elevated temperature) have been compared, and tissue-specific differences could be found, with muscles, gills and liver being the most reactive tissues (Madeira et al. 2016). The authors concluded that if individuals are not able to adapt to elevated temperatures, lower reproductive success, reduced growth and disease resistance would most likely occur (Madeira et al. 2016). Sea anemone bleaching (loss of symbiotic zooxanthellae) poses an important indirect effect of global warming for anemonefishes. It has been shown that juveniles of $A$. chrysopterus living in bleached sea anemones (H. magnifica) had an increased standard metabolic rate (up to $8 \%$ ) when compared to juveniles from unbleached sea anemones (Norin et al. 2018). The authors suggested that this increased minimum cost of living might result in reduced fitness (revised energy allocation) such as reduced growth rate, spawning frequency or lower fecundity. In the same species, it has been shown that fish living in bleached hosts experienced changes in stress and reproductive hormones (cortisol and 11-KT and 17 $\beta$-estradiol, respectively) (Beldade et al. 2017). Spawning frequency and clutch sizes were lower than in unbleached hosts (respectively, $51 \%$ and $64 \%$ ), while egg mortality was higher (38\%), leading to an overall fecundity decrease of $73 \%$. However, after host recovery, all hormonal and reproductive parameters went back to their pre-bleaching levels. This strongly suggests a key role of hormonal response plasticity in fish acclimation to climate changes (Beldade et al. 2017). Similarly, a decrease in egg production in bleached anemone has been reported for A. polymnus (Saenz-Agudelo et al. 2011). None of the previously mentioned studies reported mortality of adult fish subsequent to a bleaching event. However, by following two consecutive bleaching events, Hayashi and Reimer (2020) showed that host anemones took longer to recover after the second bleaching and that one individual even completely disappeared, together with the anemonefish pair living in it. This study indicates that if temperature abnormalities are to happen regularly, sea anemone resilience to bleaching might be impaired, which can have direct consequences for anemonefishes. Another indirect effect of global warming is ocean acidification. Indeed, when reared under simulated ocean acidification conditions, olfactory and auditory abilities of anemonefish larvae were disrupted, which usually provide important cues to locate the reef and their hosts (Munday et al. 2008; Dixson et al. 2010; Simpson et al. 2011; Holmberg et al. 2019). Noise induced by humans is classified as a form of pollution. Indeed, a study showed that embryos of A. melanopus reared under the influence of playback boat noise exhibited faster heart rates (about 10\% increase of cardiovascular activity) than ambient reef controls (Fakan and McCormick 2019). Although survival rates of embryos subjected to noise did not change, it is possible that embryogenesis is nevertheless negatively affected, leading to larvae and juveniles with reduced fitness (Fakan and McCormick 2019). Besides boat noise, anemonefishes can also be directly affected by other recreational activities such as scuba diving. Indeed, divers tend to approach these iconic fishes as closely as possible, but this human attitude could induce changes in the behavior and stress level of the fish (Hayashi et al. 2019a). In the long run, repeated human presence could affect anemonefish fitness by impairing essential behaviors such as courtship, egg care and feeding (Nanninga et al. 2017). Another drawback of their popularity is that anemonefishes are highly targeted by the aquarium trade. Indeed, the same attributes that make them good model organisms attract aquarists (longevity and exotic symbiosis) and permit easy harvesting in their natural environment (Shuman et al. 2005). Pomacentrids represent around $76 \%$ of wild-caught ornamental fish imported in the United States, with A. percula and A ocellaris in fifth place (after four species of damselfish) (Rhyne et al. 2012), even though they can be captive-bred easily. Anemonefishes represent up to $57 \%$ of all collected organisms in the Philippines (Shuman et al. 2005). There, exploited sites exhibit lower anemonefish biomass than protected sites, and fish size distribution tends to be skewed toward small fish. For A. clarkii, even the number of individuals present in exploited sites was lower, and similar results were observed for the anemone $H$. crispa (Shuman et al. 2005). Those results reflect the nonnegligible impact of aquarium trade on anemonefishes and host anemone populations.

Another human impact that has been studied is coastline anthropization. Recent studies showed that it could not only lead to low replenishment rates but also affect community structures and diversity of anemonefishes (Hayashi et al. 2019b; Hayashi et al. 2020).

While many aspects of anemonefishes biology and ecology have been studied, very little has been done to integrate those findings in applied fields such as conservation biology (but see Planes et al. 2009; Hayashi et al. 2019b, 2020), which, in the actual context of ever-growing human pressures, should be one of the priorities of the research community.

\subsubsection{Host Recognition and Settlement Clues}

Numerous studies have focused on the symbiotic relationship between anemonefishes and their host anemones, with the aim to understand how juvenile recruitment occurs. Although it is well documented that anemonefishes can distinguish different host anemones and their health status (bleached vs. unbleached) using chemical cues (Murata et al. 1986; Arvedlund and Nielsen 1996; Arvedlund et al. 1999; Miyagawa-Kohshima et al. 2014; Scott and Dixson 2016), composition and structure of these chemicals still remain unknown. A study found an upregulation of otx2 expression, a transcription factor frequently associated with olfactory imprinting, in larvae which were exposed to settlement odors compared with no-odor control larvae of $A$. percula (Veilleux et al. 2013). This chemical imprinting is believed to occur during late embryonic development and the first hours after hatching and is sufficient to recognize all species-specific partner host anemones regardless of the parents' host anemone (Arvedlund et al. 2000; MiyagawaKohshima et al. 2014). However, it has also been shown that anemonefishes possess a limited innate recognition 
(a)

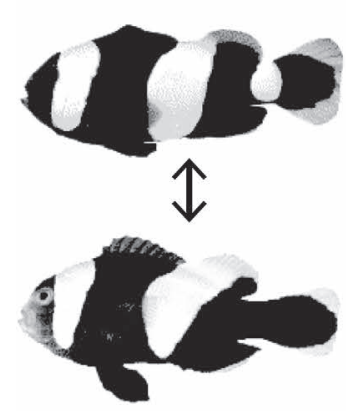

adult polymorphism (b)

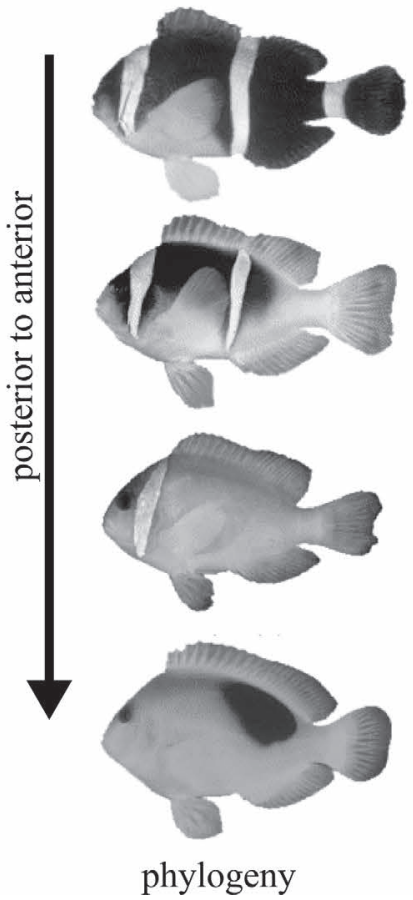

(c)

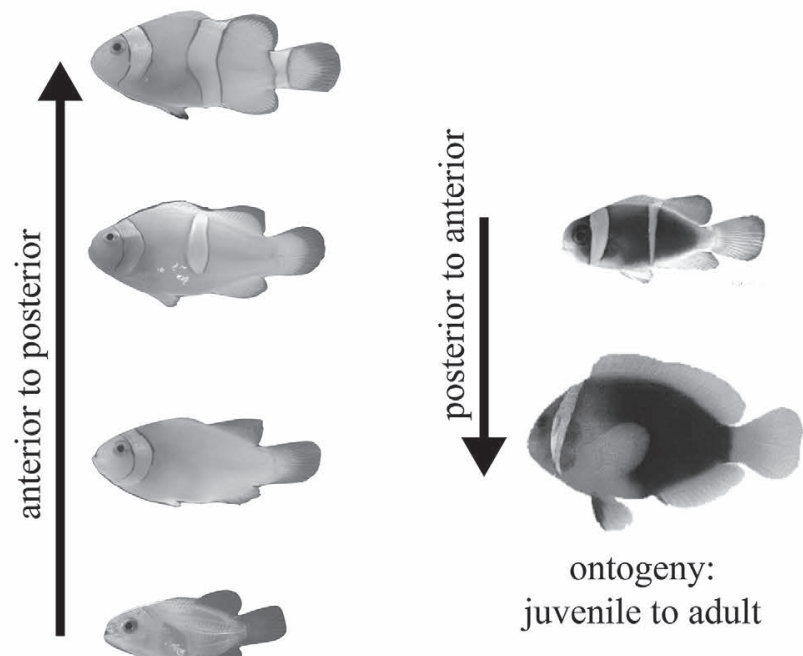

FIGURE 24.6 Evolutionary and developmental white band acquisition. Opposing trends have been described, but the underling mechanisms remain unsolved.

of partner and non-partner host anemones (MiyagawaKohshima et al. 2014). Field experiments further showed that new recruits do not discriminate between occupied and unoccupied host anemones (Elliott et al. 1995) but did encounter highly aggressive behavior from the resident fish (especially resident juveniles). Usually the new recruit would cease approaching an inhabited host after several aggressive interactions and try to locate a different host (Elliott et al. 1995). This eviction of juvenile anemonefishes has been widely noted and is believed to be the reason for the formation of sub-symbiotic partnerships if symbiotic partnership cannot be established (i.e. use of a sea anemone species that is not preferred) (Miyagawa-Kohshima et al. 2014). Most studies on anemonefish settlement have focused on the cues involved when selecting a host anemone, but cues to settle out of the plankton into the benthic reef habitat are less well investigated. They are unlikely to be the same, as it has been shown that chemical cues from anemones can only guide juveniles if they are relatively close to and downstream of an anemone (typically $2 \mathrm{~m}$, with a maximum around $8 \mathrm{~m}$ ) (Elliott et al. 1995). Due to the relative ease of obtaining naive larvae (i.e. aquarium-raised without sea anemone contact), field experiments can be conducted to validate experimental hypotheses. Once we have a better understanding of anemonefish settlement, we will be able to investigate how other coral reef fish larvae select nurseries and/or microhabitats. Selection of an appropriate substrate is of great importance for young fish, as it will ultimately determine their survival and breeding success.

\subsubsection{Evolutionary MeChanisms}

Anemonefish phylogeny has been used to investigate how hybridization and species diversification are linked (Litsios and Salamin 2014). This phylogeny was also used to compared the evolution rate of anemonefishes at both intraand interspecific scales (i.e. micro- and macro- evolution) (Rolland et al. 2018). Other new approaches, such as quantitative genetics, might also provide a better understanding of evolutionary mechanisms. This kind of approach assesses how phenotypes are shaped given the relatedness between individuals sharing similar traits and the environment in which they are living (Thomson et al. 2018). For example, Salles et al. (2020) estimated the proportion of variance in lifetime reproductive success (LRS) explained by genetic and environmental factors. When compared to environment, genetics play a minor role, resulting in low heritability and evolvability. This suggests that in its current state, the population potential for evolutionary change is very limited, highlighting the importance of plasticity to enable rapid adaptive responses. Another complex feature observed in anemonefishes is color polymorphism, which has been noted to occur at multiple scales, with melanization being the predominant one (see Figure 24.1 for an example in A. clarkii). Geographical variation in coloration is common among widely distributed species, but sympatric variations have also been reported in populations in which sexual dichromatism and ontogenetic differences govern pigmentation (Moyer 1976; Fautin and Allen 1997). A suite 
of interacting and conditional ecological factors encompassing social rank, host anemone species and location had been identified as the primary factors predicting distribution of melanistic morphs (Militz et al. 2016). However, phylogenetic studies on melanistic $A$. clarkii showed that specimens cluster by color rather than geographical origin: a melanistic specimen from Bali is more closely related to another melanistic individual originating from Papua New Guinea than to a syntopic orange A. clarkii (Litsios et al. 2014a). Another common polymorphic feature of anemonefish color pattern is the variation of band number, regularly observed in A. clarkii, A. melanopus and A. plolymnus (Figure 24.6a). This suggests complex mechanisms might be involved in anemonefish polymorphism. Salis and colleagues (2018b) mapped the occurrence and number of bands on the phylogeny to reconstruct the ancestral state and could show that the diversification of anemonefish color pattern results from successive caudal to rostral losses of bands during evolution (Figure 24.6b). This is in contrast with the developmental acquisition of bands, which appear in an anterior to posterior gradient (Figure 24.6c). Interestingly, juveniles of some species have supplementary bands that disappear later caudorostrally (Figure 24.6d). The reduction of band number during ontogeny matches the sequence of band loss during evolution, demonstrating that diversification in color pattern among anemonefish lineages resulted from changes in developmental processes. The functional aspect of anemonefish skin color and pattern remains unclear. However, it has been suggested that color patterns may (i) be used in advertising social rank (Fautin and Allen 1997; Militz et al. 2016), (ii) signal individual identity (Fricke 1973; Buston 2003a), (iii) provide disruptive coloration (Salis et al. 2018b) and (iv) be used for species recognition (Salis et al. 2018b; Salis et al. 2019b). Yet developmental mechanisms underlying the color pattern formation have still not been identified. However, a Turing-like model (that patterns zebrafish or angelfish, for example) cannot explain the appearance and/or disappearance of bands during ontogeny, thus suggesting that band formation is controlled by specific patterning mechanisms that remain to be analyzed. The dorsal fin might act as a spatial reference, since its size and geometry have been significantly correlated with the number of white bands (Salis et al. 2018b). Given the increase in interdisciplinary studies, considerable improvement in the understanding of evolutionary mechanisms should be expected in the coming years.

\subsubsection{Biomedical Research}

Anemonefishes are a promising model system for biomedical research, even though studies in this field are limited so far. On one hand, they have a relatively long life span and, on the other hand, their ability to avoid nematocyst discharge is rare among vertebrates. Anemonefishes are one of a few species that offer the opportunity to study longevity and aging. Indeed, they have a long life expectancy, which is approximately six times longer than that predicted for other small fish (Buston and García 2007; Sahm et al. 2019), and they reproduce monthly all year around. Using anemonefish, a recent study (Sahm et al. 2019) suggested that the mitonuclear balance (i.e. balance between expression of nuclear and mitochondrially encoded mitochondrial proteins) plays a key role in aging, which opens the gate to explore those genetic pathways involved.

Although many studies have attempted to unveil how anemonefishes avoid the negative effects of nematocyst stinging, there are still many open questions and various competing hypotheses (see Section 24.3). Indeed, a field study with several species of anemonefish showed that new naive recruits (around $20 \mathrm{dph}$ ) are able to enter their host anemones without being harmed on the first attempt (Elliott et al. 1995). Occasionally, the new recruits adhered to the tentacle but usually could break free and, after a short acclimation process, could enter unharmed. From a biomedical standpoint, it is of great interest, as understanding how anemonefishes avoid being stung by the hosts' nematocysts might lay a foundation for possible prevention and therapy of negative human interactions with jellyfish, for example. Additionally and rather unexpectedly, the anemonefish queuing system has been used to serve as the basis of a novel brain tumor segmentation algorithm (Mc and Subramanian 2016).

\subsubsection{Missing Functional Approaches}

Casas et al. (2016) performed the first de novo transcriptome analysis of wild A. bicinctus and highlighted the rapid and complex genomic responses of the brain during sex change, which is subsequently transmitted to the gonads. This transcriptomic data (Casas et al. 2016; Yang et al. 2019) will broaden our understanding not only of the physiological mechanisms involved but also of the perception and processing of external cues into a coordinated response that characterizes sex change (Lamm et al. 2015; Liu et al. 2017). Advances in molecular endocrinology, genomic and transcriptomic data in anemonefishes will allow opening new avenues in our understanding of sex change and sex determination in fishes and more widely in vertebrates. Moreover, extensive efforts have been put in by several research groups to establish micro-injection (Roux et al. 2020) and associated genome editing, such as CRISPR/Cas9 in anemonefishes (Mitchell et al. 2020). This is a much-needed toolkit to gain functional data and will be applicable to a range of research areas. Micro-injection is possible, yet mortality rates are still high, and obtaining larvae remains difficult (Mitchell et al. 2020; Roux et al. 2020). However, once established, the possibility of modifying specific genetic aspects will advance the field of anemonefish research, as well as research on coral reef fish, immensely. Although there are several pet shop mutants available with diverse color patterns, the underlying mutations and exact mechanisms have not been studied in detail.

\subsection{CONCLUSION}

This chapter summarizes the past and most recent research finding as well as future perspectives, revealing the great 
potential anemonefishes offer as emerging marine fish models. Future research on anemonefishes will complement studies on traditional model organisms in a wide variety of biological areas, from pigmentation to neurobiology. Their unique biological attributes open perspectives to tackle new questions related to aging, sexual differentiation, symbiosis, growth or even social organization. Anemonefishes have and will always remain prominent models for ecological studies, but now those can be linked with lab based evodevo approaches, which is hardly possible with other model organisms. As there is a lack of convenient experimental models for marine fishes, we hope and strongly believe that this model will find its place in the vast array of new models available for the biologists of tomorrow.

\section{BIBLIOGRAPHY}

Abdullah NS, Saad S. 2015. Rapid detection of N-acetylneuraminic acid from false clownfish using HPLC-FLD for symbiosis to host sea anemone. Asian Journal of Applied Sciences 3:858-864.

Albright R, Takeshita Y, Koweek DA, Ninokawa A, Wolfe K, Rivlin T, Nebuchina Y, Young J, Caldeira K. 2018. Carbon dioxide addition to coral reef waters suppresses net community calcification. Nature 555:516-519.

Allen GR. 1974. The anemonefish: Their classification and biology. Second edition. T.F.H. Publications Inc., Neptune City, NJ.

Allen GR, Drew J, Fenner D. 2010. Amphiprion pacificus, a new species of anemonefish (Pomacentridae) from Fiji, Tonga, Samoa, and Wallis Island. Aqua, International Journal of Ichthyology 16:10.

Allen GR, Drew J, Kaufman L. 2008. Amphiprion barberi, a new species of anemonefish (Pomacentridae) from Fiji, Tonga, and Samoa. Aqua, International Journal of Ichthyology 14:10.

Altieri AH, Harrison SB, Seemann J, Collin R, Diaz RJ, Knowlton N. 2017. Tropical dead zones and mass mortalities on coral reefs. Proceedings of the National Academy of Sciences 114:3660-3665.

Anil MK, Santhosh B, Prasad BO, George RM. 2012. Broodstock development and breeding of black-finned anemone fish Amphiprion nigripes Regan, 1908 under captive conditions. Indian Journal of Fisheries 59:77-82.

Apprill A. 2020. The role of symbioses in the adaptation and stress responses of marine organisms. Annual Review of Marine Science 12:291-314.

Arvedlund M, Larsen K, Winsor H. 2000. The embryonic development of the olfactory system in Amphiprion melanopus (Perciformes: Pomacentridae) related to the host imprinting hypothesis. Journal of the Marine Biological Association of the United Kingdom 80:1103-1109.

Arvedlund M, McCormick M, Fautin D, Bildsøe M. 1999. Host recognition and possible imprinting in the anemonefish Amphiprion melanopus (Pisces: Pomacentridae). Marine Ecology Progress Series 188:207-218.

Arvedlund M, Nielsen LE. 1996. Do the anemonefish Amphiprion ocellaris (Pisces: Pomacentridae) imprint themselves to their host sea anemone heteractis magnifica (Anthozoa: Actinidae)? Ethology 102:197-211.

Barone AN, Hayes CE, Kerr JJ, Lee RC, Flaherty DB. 2019. Acute toxicity testing of $\mathrm{TiO}_{2}$-based vs. oxybenzone-based sunscreens on clownfish (Amphiprion ocellaris). Environmental Science and Pollution Research 26:14513-14520.
Barth P, Berenshtein I, Besson M, Roux N, Parmentier E, Banaigs B, Lecchini D. 2015. From the ocean to a reef habitat: How do the larvae of coral reef fishes find their way home? A state of art on the latest advances. Vie et milieu 65:91-100.

Beldade R, Blandin A, O’Donnell R, Mills SC. 2017. Cascading effects of thermally-induced anemone bleaching on associated anemonefish hormonal stress response and reproduction. Nature Communications 8:716.

Berthelot $\mathrm{C}$ et al. 2014. The rainbow trout genome provides novel insights into evolution after whole-genome duplication in vertebrates. Nature Communications 5:3657.

Bertrand S, Brunet FG, Escriva H, Parmentier G, Laudet V, Robinson-Rechavi M. 2004. Evolutionary genomics of nuclear receptors: From twenty-five ancestral genes to derived endocrine systems. Molecular Biology and Evolution 21:1923-1937.

Berumen ML, Walsh HJ, Raventos N, Planes S, Jones GP, Starczak V, Thorrold SR. 2010. Otolith geochemistry does not reflect dispersal history of clownfish larvae. Coral Reefs 29:883-891.

Branconi R, Barbasch TA, Francis RK, Srinivasan M, Jones GP, Buston PM. 2020. Ecological and social constraints combine to promote evolution of non-breeding strategies in clownfish. Communications Biology 3:649.

Briggs JC. 1961. The East Pacific Barrier and the distribution of marine shore fishes. Evolution 15:545-554.

Buston PM. 2003a. Size and growth modification in clownfish. Nature 424:145-146.

Buston PM. 2003b. Mortality is associated with social rank in the clown anemonefish (Amphiprion percula). Marine Biology 143:811-815.

Buston, Buston PM. 2004a. Does the presence of non-breeders enhance the fitness of breeders? An experimental analysis in the clown anemonefish Amphiprion percula. Behavioral Ecology and Sociobiology 57:23-31.

Buston PM. 2004b. Territory inheritance in clownfish. Proceedings of the Royal Society of London. Series B: Biological Sciences 271. Available from https://royalsocietypublishing.org/ doi/10.1098/rsbl.2003.0156 (accessed November 8, 2020).

Buston PM, Bogdanowicz SM, Wong A, Harrison RG. 2007. Are clownfish groups composed of close relatives? An analysis of microsatellite DNA variation in Amphiprion percula. Molecular Ecology 16:3671-3678.

Buston PM, Elith J. 2011. Determinants of reproductive success in dominant pairs of clownfish: A boosted regression tree analysis: Determinants of reproductive success. Journal of Animal Ecology 80:528-538.

Buston PM, García MB. 2007. An extraordinary life span estimate for the clown anemonefish Amphiprion percula. Journal of Fish Biology 70:1710-1719.

Camp EF, Hobbs J-PA, De Brauwer M, Dumbrell AJ, Smith DJ. 2016. Cohabitation promotes high diversity of clownfishes in the Coral Triangle. Proceedings of the Royal Society B: Biological Sciences 283:20160277.

Casas L, Saborido-Rey F, Ryu T, Michell C, Ravasi T, Irigoien X. 2016. Sex change in clownfish: Molecular insights from transcriptome analysis. Scientific Reports 6:35461.

Casas L, Saenz-Agudelo P, Irigoien X. 2018. High-throughput sequencing and linkage mapping of a clownfish genome provide insights on the distribution of molecular players involved in sex change. Scientific Reports 8:4073.

Chen T-H, Hsieh C-Y, Ko F-C, Cheng J-O. 2018. Effect of the UV-filter benzophenone-3 on intra-colonial social behaviors of the false clown anemonefish (Amphiprion ocellaris). Science of The Total Environment 644:1625-1629. 
Christ MCJ, Subramanian R. 2016. Clown fish queuing and switching optimization algorithm for brain tumor segmentation. Biomedical Research 27:5.

Cleveland A, Verde EA, Lee RW. 2011. Nutritional exchange in a tropical tripartite symbiosis: Direct evidence for the transfer of nutrients from anemonefish to host anemone and zooxanthellae. Marine Biology 158:589-602.

Colleye O, Frederich B, Vandewalle P, Casadevall M, Parmentier E. 2009. Agonistic sounds in the skunk clownfish Amphiprion akallopisos: Size-related variation in acoustic features. Journal of Fish Biology 75:908-916.

Collingwood C. 1868. Rambles of a naturalist on the shores and waters of the China Sea. John Murray, London.

Cooper W, Van Hall R, Sweet E, Milewski H, DeLeon Z, Verderber A, DeLeon A, Galindo D, Lazono O. 2020. Functional morphogenesis from embryos to adults: Late development shapes trophic niche in coral reef damselfishes. Evolution \& Development 22:221-240.

Dhaneesh KV, Kumar TTA, Shunmugaraj T. 2009. Embryonic development of percula clownfish, Amphiprion percula (Lacepede, 1802). Middle-East Journal of Scientific Research 4:84-89.

Dhaneesh KV, Nanthini Devi K, Ajith Kumar TT, Balasubramanian T, Tissera K. 2012. Breeding, embryonic development and salinity tolerance of skunk clownfish Amphiprion akallopisos. Journal of King Saud University-Science 24:201-209.

Dixson DL, Munday PL, Jones GP. 2010. Ocean acidification disrupts the innate ability of fish to detect predator olfactory cues. Ecology Letters 13:68-75.

Dohna TA, Timm J, Hamid L, Kochzius M. 2015. Limited connectivity and a phylogeographic break characterize populations of the pink anemonefish, Amphiprion perideraion, in the Indo-Malay Archipelago: Inferences from a mitochondrial and microsatellite loci. Ecology and Evolution 5:1717-1733.

Elliott JK, Elliott JM, Mariscal RN. 1995. Host selection, location, and association behaviors of anemonefishes in field settlement experiments. Marine Biology 122:377-389.

Elliott JK, Lougheed SC, Bateman B, McPhee LK, Boag PT. 1999. Molecular phylogenetic evidence for the evolution of specialization in anemonefishes. Proceedings of the Royal Society of London. Series B: Biological Sciences 266:677-685.

Elliott JK, Mariscal RN. 1997. Acclimation or innate protection of anemonefishes from sea anemones? Copeia:284-289.

Elliott JK, Mariscal RN. 2001. Coexistence of nine anemonefish species: Differential host and habitat utilization, size and recruitment. Marine Biology 138:23-36.

Fakan EP, McCormick MI. 2019. Boat noise affects the early life history of two damselfishes. Marine Pollution Bulletin 141:493-500.

Fautin DG. 1988. Sea anemones of Madang Province. Science in New Guinea 14:22-29.

Fautin DG. 1991. The anemonefish symbiosis: What is known and what is not? Symbiosis 10:23, 46.

Fautin DG, Allen GR. 1992. Field guide to anemonefishes and their host sea anemones. Western Australian Museum. Available from https://books.google.fr/books?id=WRLGjwEACAAJ.

Fautin DG, Allen GR. 1997. Anemone fishes and their host sea anemones: A guide for aquarists and divers. Rev. edition. Western Australian Museum, Perth, WA.

Frédérich B, Parmentier E, editors. 2016. Biology of damselfishes. CRC Press, Taylor \& Francis Group, Boca Raton.

Fricke HW. 1973. Individual partner recognition in fish: Field studies on Amphiprion bicinctus. Die Naturwissenschaften 60:204-205.
Fricke HW, Fricke S. 1977. Monogamy and sex change by aggressive dominance in coral reef fish. Nature 266:830-832.

Futuyma DJ, Moreno G. 1988. The evolution of ecological specialization. Annual Review of Ecology and Systematics 19:207-233.

Gainsford A, Jones GP, Gardner MG, van Herwerden L. 2020. Characterisation and cross-amplification of 42 microsatellite markers in two Amphiprion species (Pomacentridae) and a natural hybrid anemonefish to inform genetic structure within a hybrid zone. Molecular Biology Reports 47:1521-1525.

Geffroy B, Douhard M. 2019. The adaptive sex in stressful environments. Trends in Ecology \& Evolution 34:628-640.

Gemmell NJ, Todd EV, Goikoetxea A, Ortega-Recalde O, Hore TA. 2019. Natural sex change in fish. Pages 71-117 in Current topics in developmental biology book series: Sex determination in vertebrates. Elsevier, New Zealand.

Ghosh J, Wilson RW, Kudoh T. 2009. Normal development of the tomato clownfish Amphiprion frenatus: Live imaging and in situ hybridization analyses of mesodermal and neurectodermal development. Journal of Fish Biology 75:2287-2298.

Glasauer SMK, Neuhauss SCF. 2014. Whole-genome duplication in teleost fishes and its evolutionary consequences. Molelucar Genetics and Genomics 289:1045-1060.

Godwin JR. 1994. Behavioural aspects of protandrous sex change in the anemonefish, Amphiprion melanopus, and endocrine correlates. Animal Behaviour 48:551-567.

Godwin JR, Crews D, Warner RR. 1996. Behavioural sex change in the absence of gonads in a coral reef fish. Proceedings of the Royal Society of London. Series B: Biological Sciences 263:1683-1688.

Godwin JR, Thomas P. 1993. Sex change and steroid profiles in the protandrous anemonefish Amphiprion melanopus (Pomacentridae, teleostei). General and Comparative Endocrinology 91:144-157.

Goikoetxea A, Todd EV, Gemmell NJ. 2017. Stress and sex: Does cortisol mediate sex change in fish? Reproduction 154:R149-R160.

Green BS. 2004. Embryogenesis and oxygen consumption in benthic egg clutches of a tropical clownfish, Amphiprion melanopus (Pomacentridae). Comparative Biochemistry and Physiology Part A: Molecular \& Integrative Physiology 138:33-38.

Gunasekaran K, Sarvanakumar A, Selvam D, Mahesh R. 2017. Embryonic and larval developmental stages of sebae clownfish Amphiprion sebae (Bleeker 1853) in captive condition. Indian Journal of Marine Sciences 46:8.

Hayashi K, Reimer JD. 2020. Five-year study on the bleaching of anemonefish-hosting anemones (Cnidaria: Anthozoa: Actiniaria) in subtropical Okinawajima Island. Regional Studies in Marine Science 35:101240.

Hayashi K, Tachihara K, Reimer JD. 2018. Patterns of coexistence of six anemonefish species around subtropical Okinawa-jima Island, Japan. Coral Reefs 37:1027-1038.

Hayashi K, Tachihara K, Reimer JD. 2019a. Species and sexual differences in human-oriented behavior of anemonefish at Okinawa Island, Japan. Marine Ecology Progress Series 616:219-224.

Hayashi K, Tachihara K, Reimer JD. 2019b. Low density populations of anemonefish with low replenishment rates on a reef edge with anthropogenic impacts. Environmental Biology of Fishes 102:41-54.

Hayashi K, Tachihara K, Reimer JD. 2020. Loss of natural coastline influences species diversity of anemonefish and host anemones in the Ryukyu Archipelago. Aquatic Conservation: Marine and Freshwater Ecosystems. doi:10.1002/aqc.3435.

He S, Planes S, Sinclair-Taylor TH, Berumen ML. 2019. Diagnostic nuclear markers for hybrid Nemos in Kimbe Bay, 
PNG-Amphiprion chrysopterus x Amphiprion sandaracinos hybrids. Marine Biodiversity 49:1261-1269.

Herbert NA, Bröhl S, Springer K, Kunzmann A. 2017. Clownfish in hypoxic anemones replenish host $\mathrm{O}_{2}$ at only localised scales. Scientific Reports 7:6547.

Holmberg RJ et al. 2019. Ocean acidification alters morphology of all otolith types in Clark's anemonefish (Amphiprion clarkii). Peer Journal of Life and Environment 7:e6152.

Holzer G, Besson M, Lambert A, Barth P, Gillet B, Hughes S, Leulier F, Viriot L, Lecchini D, Laudet V. 2017. Fish larval recruitment to reefs is a thyroid hormone-mediated metamorphosis sensitive to the pesticide chlorpyrifos. Elife e27595.

Hotaling S, Kelley JL. 2019. The rising tide of high-quality genomic resources. Molecular Ecology Resources 19:567-569.

Hughes TP et al. 2018. Global warming transforms coral reef assemblages. Nature 556:492-496.

Irion U, Nüsslein-Volhard C. 2019. The identification of genes involved in the evolution of color patterns in fish. Current Opinion in Genetics \& Development 57:31-38.

Iwata E, Mikami K, Manbo J, Moriya-Ito K, Sasaki H. 2012. Social interaction influences blood cortisol values and brain aromatase genes in the protandrous false clown anemonefish, Amphiprion ocellaris. Zoological Science 29:849-855.

Jaillon O et al. 2004. Genome duplication in the teleost fish Tetraodon nigroviridis reveals the early vertebrate protokaryotype. Nature 431:946-957.

Jones GP, Planes S, Thorrold SR. 2005. Coral reef fish larvae settle close to home. Current Biology 15:1314-1318.

Kavanagh KD, Alford RA. 2003. Sensory and skeletal development and growth in relation to the duration of the embryonic and larval stages in damselfishes (Pomacentridae): Development and growth in damselfishes. Biological Journal of the Linnean Society 80:187-206.

Kawaguchi M, Takahashi H, Takehana Y, Naruse K, Nishida M, Yasumasu S. 2013. Sub-functionalization of duplicated genes in the evolution of nine-spined stickleback hatching enzyme: Sub-functionalization of hatching enzyme. Journal of Experimental Zoology Part B: Molecular and Developmental Evolution 320:140-150.

Kawakami Y, Nozaki J, Seoka M, Kumai H, Ohta H. 2008. Characterization of thyroid hormones and thyroid hormone receptors during the early development of Pacific bluefin tuna (Thunnus orientalis). General and Comparative Endocrinology 155:597-606.

Kirkwood T. 1977. Evolution of aging. Nature 270:301-304.

Kobayashi Y, Horiguchi R, Miura S, Nakamura M. 2010. Sex- and tissue-specific expression of P450 aromatase (cyp19a1a) in the yellowtail clownfish, Amphiprion clarkii. Comparative Biochemistry and Physiology Part A: Molecular \& Integrative Physiology 155:237-244.

Kobayashi Y, Nagahama Y, Nakamura M. 2013. Diversity and plasticity of sex determination and differentiation in fishes. Sexual Development 7:115-125.

Krishna R. 2018. Larval development and growth of red saddleback anemonefish, Amphiprion ephippium (Bloch, 1790) under captive conditions. Indian Journal of Geo-Marine Sciences 47:2421-2428.

Lamm MS, Liu H, Gemmell NJ, Godwin JR. 2015. The need for speed: Neuroendocrine regulation of socially-controlled sex change. Integrative and Comparative Biology 55:307-322.

Laudet V. 2011. The origins and evolution of vertebrate metamorphosis. Current Biology 21:R726-R737.

Lehmann R et al. 2019. Finding Nemo's genes: A chromosome-scale reference assembly of the genome of the orange clownfish Amphiprion percula. Molecular Ecology Resources 19:570-585.
Leis JM. 1991. The pelagic stage of reef fishes: The larval biology of coral reef fishes. Pages 183-230 in Sale PF, editor. The ecology of fishes on coral reefs. Academic Press, San Diego.

Leis JM, Siebeck U, Dixson DL. 2011. How Nemo finds home: The neuroecology of dispersal and of population connectivity in larvae of marine fishes. Integrative and Comparative Biology 51:826-843.

Li J-T, Hou G-Y, Kong X-F, Li C-Y, Zeng J-M, Li H-D, Xiao G-B, Li X-M, Sun X-W. 2015. The fate of recent duplicated genes following a fourth-round whole genome duplication in a tetraploid fish, common carp (Cyprinus carpio). Scientific Reports 5:8199.

Liew HJ, Ambak MA, Abol-Munafi AB, Chuah TS. 2006. Embryonic development of clownfish Amphiprion ocellaris under laboratory conditions. Journal of Sustainability Science and Management 1:64-73.

Litsios G, Pearman PB, Lanterbecq D, Tolou N, Salamin N. 2014b. The radiation of the clownfishes has two geographical replicates. Journal of Biogeography 41:2140-2149.

Litsios G, Salamin N. 2014. Hybridisation and diversification in the adaptive radiation of clownfishes. BMC Evolutionary Biology 14:245.

Litsios G, Sims CA, Wüest RO, Pearman PB, Zimmermann NE, Salamin N. 2012a. Mutualism with sea anemones triggered the adaptive radiation of clownfishes. BMC Evolutionary Biology 12:212.

Litsios G, Sims CA, Wüest RO, Pearman PB, Zimmermann NE, Salamin N. 2012b. Mutualism with sea anemones triggered the adaptive radiation of clownfishes. BMC Evolutionary Biology 12:1.

Liu H, Todd EV, Lokman PM, Lamm MS, Godwin JR, Gemmell NJ. 2017. Sexual plasticity: A fishy tale. Molecular Reproduction and Development 84:171-194.

Lubbock R. 1981. The clownfish/anemone symbiosis: A problem of cell recognition. Parasitology 82(159):173.

Lubbock R, Smith DC. 1980. Why are clownfishes not stung by sea anemones? Proceedings of the Royal Society of London. Series B: Biological Sciences 207:35-61. Royal Society.

Madeira C, Madeira D, Diniz MS, Cabral HN, Vinagre C. 2016. Thermal acclimation in clownfish: An integrated biomarker response and multi-tissue experimental approach. Ecological Indicators 71:280-292.

Madhu R, Madhu K, Retheesh T. 2012. Life history pathways in false clown Amphiprion ocellaris Cuvier, 1830: A journey from egg to adult under captive condition. Journal of Marine Biological Association of India 54:77-90.

Marcionetti A, Rossier V, Bertrand JAM, Litsios G, Salamin N. 2018. First draft genome of an iconic clownfish species (Amphiprion frenatus). Molecular Ecology Resources 18:1092-1101.

Marcionetti A, Rossier V, Roux N, Salis P, Laudet V, Salamin N. 2019. Insights into the genomics of clownfish adaptive radiation: Genetic basis of the mutualism with sea anemones. Genome Biology and Evolution 11:869-882.

Mariscal RN. 1970. The nature of the symbiosis between Indo-Pacific anemone fishes and sea anemones. Marine Biology 6:58-65.

Maytin AK, Davies SW, Smith GE, Mullen SP, Buston PM. 2018. De novo transcriptome assembly of the clown anemonefish (Amphiprion percula): A new resource to study the evolution of fish color. Frontiers in Marine Science 5:284.

Mebs D. 2009. Chemical biology of the mutualistic relationships of sea anemones with fish and crustaceans. Toxicon 54:1071-1074.

Medawar P. 1952. An unsolved problem of biology: Printed lecture. University College London, London.

Meyer A, Schartl M. 1999. Gene and genome duplications in vertebrates: The one-to-four (-to-eight in fish) rule and the 
evolution of novel gene functions. Current Opinion in Cell Biology 11:699-704.

Militz TA, McCormick MI, Schoeman DS, Kinch J, Southgate PC. 2016. Frequency and distribution of melanistic morphs in coexisting population of nine clownfish species in Papua New Guinea. Marine Biology 163:200-210.

Mills SC, Mourier J, Galzin R. 2010. Plasma cortisol and 11-ketotestosterone enzyme immunoassay (EIA) kit validation for three fish species: The orange clownfish Amphiprion percula, the orangefin anemonefish Amphiprion chrysopterus and the blacktip reef shark Carcharhinus melanopterus. Journal of Fish Biology 77:769-777.

Mitchell J. 2005. Queue selection and switching by false clown anemonefish, Amphiprion ocellaris. Animal Behaviour 69:643-652.

Mitchell LJ, Tettamanti V, Marshall JN, Cheney KL, Cortesi F. 2020. CRISPR/Cas9-mediated generation of biallelic G0 anemonefish (Amphiprion ocellaris) mutants. preprint. Molecular Biology. Available from http://biorxiv.org/lookup/ doi/10.1101/2020.10.07.330746 (accessed November 15, 2020).

Miura S, Kobayashi Y, Bhandari RK, Nakamura M. 2013. Estrogen favors the differentiation of ovarian tissues in the ambisexual gonads of anemonefish Amphiprion clarkii: The role of estrogen for gonad in anemonefish. Journal of Experimental Zoology Part A: Ecological Genetics and Physiology 319:560-568.

Miyagawa-Kohshima K et al. 2014. Embryonic learning of chemical cues via the parents' host in anemonefish (Amphiprion ocellaris). Journal of Experimental Marine Biology and Ecology 457:160-172.

Moyer JT. 1976. Geographical variation and social dominance in Japanese populations of the anemonefish Amphiprion clarkii. Japane Journal of Ichthyology 23:12-22.

Moyer JT. 1980. Influence of temperate waters on the behavior of the tropical anemonefish Amphiprion clarkii at Miyake-jima, Japan. Bulletin of Marine Science:261-272.

Munday PL, Buston P, Warner R. 2006. Diversity and flexibility of sex-change strategies in animals. Trends in Ecology \& Evolution 21:89-95.

Munday PL, Jones GP, Pratchett MS, Williams AJ. 2008. Climate change and the future for coral reef fishes. Fish and Fisheries 9:261-285.

Murata M, Miyagawa-Kohshima K, Nakanishi K, Naya Y. 1986. Characterization of compounds that induce symbiosis between sea anemone and anemone fish. Science 234:585-587.

Nanninga GB, Côté IM, Beldade R, Mills SC. 2017. Behavioural acclimation to cameras and observers in coral reef fishes. Ethology 123:705-711.

Nanninga GB, Saenz-Agudelo P, Zhan P, Hoteit I, Berumen ML. 2015. Not finding Nemo: Limited reef-scale retention in a coral reef fish. Coral Reefs 34:383-392.

Nedosyko AM, Young JE, Edwards JW, Burke da Silva K. 2014. Searching for a toxic key to unlock the mystery of anemonefish and anemone symbiosis. PLoS One 9:e98449.

Nelson JS, Grande T, Wilson MVH. 2016. Fishes of the world. Fifth edition. John Wiley \& Sons, Hoboken, NJ.

Nguyen H-TT, Dang BT, Glenner H, Geffen AJ. 2020. Cophylogenetic analysis of the relationship between anemonefish Amphiprion (Perciformes: Pomacentridae) and their symbiotic host anemones (Anthozoa: Actiniaria). Marine Biology Research 16:117-133.

Nieuwenhuys R, ten Donkelaar HJ, Nicholson C. 1998. The central nervous system of vertebrates. Springer Berlin Heidelberg, Berlin, Heidelberg. Available from http://link.springer.com/ 10.1007/978-3-642-18262-4 (accessed November 13, 2020).
Norin T, Mills SC, Crespel A, Cortese D, Killen SS, Beldade R. 2018. Anemone bleaching increases the metabolic demands of symbiont anemonefish. Proceedings of the Royal Society B: Biological Sciences 285:20180282.

Ochi H. 1985. Temporal patterns of breeding and larval settlement in a temperate population of the tropical anemonefish, Amphiprion clarkii. Japanese Journal of Ichthyology 32:248-257.

Ohno S. 1970. Evolution by gene duplication. Springer Berlin Heidelberg, Berlin, Heidelberg.

Olivotto I, Geffroy B. 2017. Clownfish. Pages 177-199 in Calado R, Olivotto I, Oliver MP, Holt GJ, editors. Marine ornamental species aquaculture. First edition. Wiley Online Books, Chichester, West Sussex, UK.

Ollerton J, McCollin D, Fautin DG, Allen GR. 2007. Finding NEMO: Nestedness engendered by mutualistic organization in anemonefish and their hosts. Proceedings of the Royal Society B: Biological Sciences 274:591-598.

Onimaru K, Kuraku S. 2018. Inference of the ancestral vertebrate phenotype through vestiges of the whole-genome duplications. Briefings in Functional Genomics 17:352-361.

Ortega-Recalde O, Goikoetxea A, Hore TA, Todd EV, Gemmell NJ. 2020. The genetics and epigenetics of sex change in fish. Annual Review of Animal Biosciences 8:47-69.

Paris CB, Atema J, Irisson J-O, Kingsford M, Gerlach G, Guigand CM. 2013. Reef odor: A wake up call for navigation in reef fish larvae. PLoS One 8:e72808.

Park MS, Shin HS, Kil G-S, Lee J, Choi CY. 2011. Monitoring of $\mathrm{Na}+\mathrm{K}+-$ ATPase mRNA expression in the cinnamon clownfish, Amphiprion melanopus, exposed to an osmotic stress environment: Profiles on the effects of exogenous hormone. Ichthyological Research 58:195-201.

Parmentier E, Colleye O, Fine ML, Frederich B, Vandewalle P, Herrel A. 2007. Sound production in the clownfish Amphiprion clarkii. Science 316:1006.

Parmentier E, Colleye O, Mann D. 2009. Hearing ability in three clownfish species. Journal of Experimental Biology 212:2023-2026.

Parmentier E, Lagardère JP, Vandewalle P, Fine ML. 2005. Geographical variation in sound production in the anemonefish Amphiprion akallopisos. Proceedings of the Royal Society B: Biological Sciences 272:1697-1703.

Patkaew S, Direkbusarakom S, Tantithakura O. 2014. A simple method for cell culture of 'Nemo' ocellaris clownfish (Amphiprion ocellaris, Cuvier 1830). Cell Biology International Reports 7.

Patterson LB, Parichy DM. 2019. Zebrafish pigment pattern formation: Insights into the development and evolution of adult form. Annual Review of Genetics 53:505-530.

Planes S, Jones GP, Thorrold SR. 2009. Larval dispersal connects fish populations in a network of marine protected areas. Proceedings of the National Academy of Sciences 106:5693-5697.

Porter SN, Humphries MS, Buah-Kwofie A, Schleyer MH. 2018. Accumulation of organochlorine pesticides in reef organisms from marginal coral reefs in South Africa and links with coastal groundwater. Marine Pollution Bulletin 137:295-305.

Pratte ZA, Patin NV, McWhirt ME, Caughman AM, Parris DJ, Stewart FJ. 2018. Association with a sea anemone alters the skin microbiome of clownfish. Coral Reefs 37:1119-1125.

Putra DF, Abol-Munafi AB, Muchlisin ZA, Chen J-C. 2012. Preliminary studies on morphology and digestive tract development of tomato clownfish, Amphiprion frenatus under captive condition. International Journal of the Bioflux Society AACL Bioflux 5:8.

Randall JE. 1955. Fishes of the Gilbert Islands. Atoll Research Bulletin 47:1-243.

Randall JE, Fautin D. 2002. Fishes other than anemonefishes that associate with sea anemones. Coral Reefs 21:188-190. 
Rattanayuvakorn S, Mungkornkarn P, ThongpanA, Chatchavalvanich K. 2005. Embryonic development of saddleback anemonefish, Amphiprion polymnus, Linnaeus (1758). Natural Science 39:455-463.

Rhyne AL, Tlusty MF, Schofield PJ, Kaufman L, Morris JA, Bruckner AW. 2012. Revealing the appetite of the marine aquarium fish trade: The volume and biodiversity of fish imported into the United States. PLoS One 7:e35808.

Robertson DR, Grove JS, McCosker JE. 2004. Tropical transpacific shore fishes. Pacific Science 58:507-565.

Rodrigues FSLM, Yang X, Nikaido M, Liu Q, Kelsh RN. 2012. A simple, highly visual in vivo screen for anaplastic lymphoma kinase inhibitors. ACS Chemical Biology 7:1968-1974.

Rolland J, Silvestro D, Litsios G, Faye L, Salamin N. 2018. Clownfishes evolution below and above the species level. Proceedings of the Royal Society B: Biological Sciences 285:20171796.

Roux N, Lami R, Salis P, Magré K, Romans P, Masanet P, Lecchini D, Laudet V. 2019a. Sea anemone and clownfish microbiota diversity and variation during the initial steps of symbiosis. Scientific Reports 9:19491.

Roux N, Salis P, Lambert A, Logeux V, Soulat O, Romans P, Frédérich B, Lecchini D, Laudet V. 2019b. Staging and normal table of postembryonic development of the clownfish (Amphiprion ocellaris). Developmental Dynamics 248:545-568.

Roux N, Salis P, Lee S-H, Besseau L, Laudet V. 2020. Anemonefish, a model for eco-evo-devo. EvoDevo 11:20.

Roux N, Logeux V, Trouillard N., Pillot R Magré K, Salis P, Lecchini D, Besseau L, Laudet V, Romans P. 2021. A star is born again: Methods for larval rearing of an emerging model organism, the False clownfish Amphiprion ocellaris. Journal of Experimental Zoology Part B: Molecular and Developmental Evolution, Jun: 336(4): 376-85.

Rueger T, Barbasch TA, Wong MYL, Srinivasan M, Jones GP, Buston PM. 2018. Reproductive control via the threat of eviction in the clown anemonefish. Proceedings of the Royal Society B: Biological Sciences 285:20181295.

Saenz-Agudelo P, Jones GP, Thorrold SR, Planes S. 2011. Detrimental effects of host anemone bleaching on anemonefish populations. Coral Reefs 30:497-506.

Sahm A, Almaida-Pagán P, Bens M, Mutalipassi M, Lucas-Sánchez A, de Costa Ruiz J, Görlach M, Cellerino A. 2019. Analysis of the coding sequences of clownfish reveals molecular convergence in the evolution of lifespan. BMC Evolutionary Biology 19:89.

Salis P et al. 2019a. Developmental and comparative transcriptomic identification of iridophore contribution to white barring in clownfish. Pigment Cell \& Melanoma Research 32:391-402.

Salis P, Lorin T, Laudet V, Frédérich B. 2019b. Magic traits in magic fish: Understanding color pattern evolution using reef fish. Trends in Genetics 35:265-278.

Salis P, Roux N, Lecchini D, Laudet V. 2018a. The post-embryonic development of Amphiprion perideraion reveals a decoupling between morphological and pigmentation change. Société Française d'Ichtyologie. Available from http://sfi-cybium. $\mathrm{fr} / \mathrm{fr} /$ post-embryonic-development-amphiprion-perideraionreveals-decoupling-between-morphological-and (accessed November 13, 2020).

Salis P, Roux N, Soulat O, Lecchini D, Laudet V, Frédérich B. 2018b. Ontogenetic and phylogenetic simplification during white stripe evolution in clownfishes. BMC Biology 16(1):90.

Salis P, Lee SH, Roux N, Lecchini D, Laudet V. 2021. The real Nemo movie: Description of embryonic development in Amphiprion ocellaris from first division to hatching. Developmental Dynamics, May 7.

Salles OC, Almany GR, Berumen ML, Jones GP, Saenz-Agudelo P, Srinivasan M, Thorrold SR, Pujol B, Planes S. 2020. Strong habitat and weak genetic effects shape the lifetime reproductive success in a wild clownfish population. Ecology Letters 23:265-273.

Salles OC, Maynard JA, Joannides M, Barbu CM, Saenz-Agudelo P, Almany GR, Berumen ML, Thorrold SR, Jones GP, Planes S. 2015. Coral reef fish populations can persist without immigration. Proceedings of the Royal Society B: Biological Sciences 282:20151311.

Salles OC, Pujol B, Maynard JA, Almany GR, Berumen ML, Jones GP, Saenz-Agudelo P, Srinivasan M, Thorrold SR, Planes S. 2016. First genealogy for a wild marine fish population reveals multigenerational philopatry. Proceedings of the National Academy of Sciences 113:13245-13250.

Santini S, Polacco G. 2006. Finding Nemo: Molecular phylogeny and evolution of the unusual life style of anemonefish. Gene 385:19-27.

Schlichter D. 1968. Das Zusammenleben von Riffanemonen und Anemonenfischen. Zeitschrift für Tierpsychologie 25:933-954.

Scott A, Dixson DL. 2016. Reef fishes can recognize bleached habitat during settlement: Sea anemone bleaching alters anemonefish host selection. Proceedings of the Royal Society B: Biological Sciences 283:20152694.

Scott MW. 2008. Damsefishes and anemonefishes: The complete illustrated guide to their identification, behaviors and captive care. T. F. H. Publications, Neptune City.

Seymour J, Barbasch T, Buston P. 2018. Lunar cycles of reproduction in the clown anemonefish Amphiprion percula: Individual-level strategies and population-level patterns. Marine Ecology Progress Series 594:193-201.

Shabana NMA, Helal AM. 2006. Reproduction in captivity, broodstock rearing and embryology of the anemone fish Amphiprion bicintus inhabiting the Red Sea. Egyptian Journal of Aquatic Research 32:438-446.

Shuman CS, Hodgson G, Ambrose RF. 2005. Population impacts of collecting sea anemones and anemonefish for the marine aquarium trade in the Philippines. Coral Reefs 24:564-573.

Simpson SD, Munday PL, Wittenrich ML, Manassa R, Dixson DL, Gagliano M, Yan HY. 2011. Ocean acidification erodes crucial auditory behaviour in a marine fish. Biology Letters 7:917-920.

Southey BR, Rodriguez-Zas SL, Rhodes JS, Sweedler JV. 2020. Characterization of the prohormone complement in Amphiprion and related fish species integrating genome and transcriptome assemblies. PLoS One 15:e0228562.

Stieb SM, de Busserolles F, Carleton KL, Cortesi F, Chung W-S, Dalton BE, Hammond LA, Marshall NJ. 2019. A detailed investigation of the visual system and visual ecology of the Barrier Reef anemonefish, Amphiprion akindynos. Scientific Reports 9:16459.

Supiwong W, Tanomtong A, Pinthong K, Kaewmad P, Poungnak P, Jangsuwan N. 2015. The first chromosomal characteristics of nucleolar organizer regions and karyological analysis of pink anemonefish, Amphiprion perideraion (Perciformes, Amphiprioninae). Cytologia 80:271-278.

Tan MH, Austin CM, Hammer MP, Lee YP, Croft LJ, Gan HM. 2018. Finding Nemo: Hybrid assembly with Oxford Nanopore and Illumina reads greatly improves the clownfish (Amphiprion ocellaris) genome assembly. GigaScience 7. Available from https://academic.oup.com/gigascience/article/ doi/10.1093/gigascience/gix137/4803946 (accessed September 25, 2020).

Thomas D, Prakashand C, Gopakumar G. 2015. Spawning behaviour and embryonic development in the sebae anemonefish Amphiprion sebae (Bleeker, 1853). Indian Journal of Fisheries 62:58-65.

Thomson CE, Winney IS, Salles OC, Pujol B. 2018. A guide to using a multiple-matrix animal model to disentangle genetic 
and nongenetic causes of phenotypic variance. PLoS One 13:e0197720.

Titus BM et al. 2019. Phylogenetic relationships among the clownfish-hosting sea anemones. Molecular Phylogenetics and Evolution 139:106526.

Todd EV, Liu H, Muncaster S, Gemmell NJ. 2016. Bending genders: The biology of natural sex change in fish. Sexual Development 10:223-241.

Veilleux HD, Van Herwerden L, Cole NJ, Don EK, De Santis C, Dixson DL, Wenger AS, Munday PL. 2013. Otx2 expression and implications for olfactory imprinting in the anemonefish, Amphiprion percula. Biology Open 2:907-915.

Victor B, Wellington G. 2000. Endemism and the pelagic larval duration of reef fishes in the eastern Pacific Ocean. Marine Ecology Progress Series 205:241-248.
Williams GC. 1957. Pleiotropy, natural selection, and the evolution of senescence. Evolution 11:398-411.

Yang W, Lin B, Li G, Chen H, Liu M. 2019. Sequencing and transcriptome analysis for reproduction-related genes identification and SSRs discovery in sequential hermaphrodite Amphiprion ocellaris. Turkish Journal of Fisheries and Aquatic Sciences 19. Available from www.trjfas.org/pdf/ issue_19_12/1207.pdf (accessed November 11, 2020).

Yasir I, Qin JG. 2007. Embryology and early ontogeny of an anemonefish Amphiprion ocellaris. Journal of the Marine Biological Association of the United Kingdom 87:1025-1033.

Yu PB, Hong CC, Sachidanandan C, Babitt JL, Deng DY, Hoyng SA, Lin HY, Bloch KD, Peterson RT. 2008. Dorsomorphin inhibits BMP signals required for embryogenesis and iron metabolism. Nature Chemical Biology 4:33-41. 